\title{
LA READAPTACIÓN CULTURAL PARACAS A LA ENTIDAD NASCA: un enfoque desde el asentamiento de Cerro Córdova
}

\author{
Oscar Daniel Llanos Jacinto ${ }^{a}$
}

\begin{abstract}
Resumen
Salvo raras excepciones, la sociedad paracas del valle de Ica ha sido largamente estudiada a partir de materiales descontextualizados, entre los cuales destaca la cerámica recolectada de excavaciones clandestinas de tumbas en la cuenca de Ocucaje. A partir del análisis estilistico de estas piezas, que incluyeron también especímenes nasca, se elaboró una hipótesis que suponia un origen nasca a partir de los paracas, expresado en el conocido axioma "transición paracas-nasca». Los trabajos realizados en Cerro Córdova y aquellos que desde 2009 se realizan en Ánimas Altas en el marco de las investigaciones de los autores son los primeros de carácter sistemático en el valle bajo de Ica. Los contextos arqueológicos recuperados no reflejan ese proceso de transición cultural, sino, más bien, un proceso de paralelismo cultural seguido de una dinámica de readaptación cultural. Desde esta perspectiva, los paracas del valle de Ica se adaptarian a los nuevos esquemas politico-religiosos y hegemónicos que comenzaron a configurarse durante los inicios del Intermedio Temprano en la cuenca del río Grande de Nasca, y que caracterizaron a la entidad nasca.
\end{abstract}

Palabras clave: Cerro Córdova, Cerro Max Uble, Paracas, Nasca, Ocucaje, interacciones regionales

\section{Abstract \\ PARACAS CULTURAL READAPTATION TO THE NASCA ENTITY: AN APPROACH FROM THE SETTLEMENT OF CERRO CORDOVA}

Except rare exceptions, the Paracas society of the Ica valley has been extensively studied from decontextualized materials, including pottery collected from clandestine tomb excavations in the Ocucaje basin. From the stylistic analysis of these pieces, which also included Nasca specimens, the hypothesis was elaborated that assumed the birth from the Paracas, expressed in the well-known axiom "transition paracas-nasca». The works carried out in Cerro Córdova and those that since 2009 are carried out in Animas Altas, within the framework of the investigations of the authors, are the first of a systematic nature in the lower valley of Ica. Recovered archaeological contexts do not reflect this process of cultural transition, but rather a process of cultural parallelism, followed by cultural readaptation dynamics. From this perspective, the Paracas of the valley of Ica would adapt to the new political-religious and hegemonic schemes that began to be formed during the early Intermediate Period in the basin of the Rio Grande de Nasca, and that characterized the Nasca entity.

Keywords: Cerro Córdova, Cerro Max Uhle, Paracas, Nasca, Ocucaje, regional interaction

\footnotetext{
a CentredeRecherchesurl'AmériquePréhispanique, (CeRAP), Ecoledes HautesEtudesenSciencesSociales (EHESS). Correo electrónico: llanosja@ehess.fr
} 


\section{Introducción}

Cuando se debate acerca de los paracas — una de las manifestaciones culturales del Horizonte Temprano e inicios del Intermedio Temprano en los Andes peruanos-, es inevitable referirse a la bibliografía arqueológica del área de Ocucaje, una de las cuencas del río Ica. Numerosos estudios de materiales paracas procedentes de esta cuenca sirvieron para caracterizar aquello que define a la cultura Paracas. Efectivamente, uno de los trabajos más conocidos que aborda a los paracas fue sustentado esencialmente sobre la base de materiales colectados en diversos sitios de la cuenca de Ocucaje, pero también de otras áreas del valle de Ica. Se trata de la secuencia estilística de cerámica paracas denominada Ocucaje (Menzel et al. 1964), también concebida como una cronología. No obstante, al indagar sobre la procedencia de los materiales analizados, se observa que estos no cuentan con registros arqueológicos. Es el caso de la colección de cerámica de Ica recuperada por Uhle y depositada en Berkeley, así como el de las piezas de colecciones privadas obtenidas a través de las excavaciones fortuitas de los hacendados locales. Desde esta perspectiva, los resultados iniciales de las excavaciones efectuadas en Cerro Córdova —el sitio más imponente de toda la cuenca de Ocucaje- son los primeros que provienen de contextos arqueológicos excavados sistemáticamente. Sin duda alguna, esta información será útil para diferenciar, contrastar, asociar y comparar con las fuentes que sustentan los argumentos interpretativos acerca de la sociedad paracas y las hipótesis que suponen un origen nasca a partir de las dinámicas paracas.

\section{Cerro Córdova: Antecedentes y problemática}

Los primeros registros arqueológicos en el sitio fueron efectuados por Max Uhle en 1901, en uno de los cerros, razón por la cual este yacimiento es conocido también como Cerro Max Uhle. Los trabajos de este arqueólogo se desarrollaron en diversos sectores de la cuenca de Ocucaje, en terrenos pertenecientes a la hacienda Ocucaje, incluido Cerro Córdova. El yacimiento fue denominado Sitio A por Uhle, en el que se descubrieron entierros mezclados que contenían material paracas de estilo Ocucaje y también Nasca (Kaulicke, 1998: 49; ver Kroeberg y Strong, 1924: plate $29 \mathrm{c}, \mathrm{d}, \mathrm{e}, \mathrm{f}, \mathrm{g}$ ). El sitio A es descrito por Uhle como zona rocosa, situado en una depresión entre dos pequeńas cumbres de 10 metros y a unos 20 metros por encima de unas ruinas denominadas sitio $\mathrm{D}^{1}$ (Kroeber y Strong 1924: 100). Asimismo, señala la presencia de restos de cráneos con deformación alargada (ibid.). Los datos disponibles indican claramente que Uhle excavó en algún sector situado entre las diversas cimas rocosas que conforman Cerro Córdova; asimismo indica de manera indirecta que para entonces el sitio ya se encontraba huaqueado. Dado el carácter inicial de la investigación, Uhle parece no interesarse en aquellos especímenes de cerámica paracas, incluyéndolos quizás como parte del estilo Nasca. En efecto, el reconocimiento arqueológico de la cultura Paracas se daría recién en 1925 con los descubrimientos de Tello en la península del mismo nombre. A partir de la cerámica hallada en el sitio A y en otros yacimientos muy próximos (sitios B, C, F, H), Kroeberg y Strong plantearían la existencia de los estilos Protonascoide y Proto Nasca. ${ }^{2}$ En 1953, Pezzia Assereto excavó a unos 280 metros al sur de Cerro Córdova. En este sector, descubrió una cámara funeraria de planta rectangular de la época Paracas Tardía, que se había conservado intacta a pesar del saqueo. En ella, se registró un fardo compuesto de tejidos pintados y elementos del ajuar funerario (Pezzia 1968: 115-116). En otros sectores de las laderas del Cerro Córdova, Pezzia registró cámaras funerarias y viviendas subterráneas con paredes hechas con manojos de ramas vegetales unidas con barro (ibid.: 83). Pablo Soldi, hacendado de Ocucaje, excavó numerosas tumbas en las laderas de Cerro Córdova y del Cerro de la Cruz, situado a unos 600 metros al norte del sitio. En su registro de materiales, se describen fardos compuestos por tejidos pintados y otros decorados en la técnica estructural, así como cerámica con pintura poscocción (King 1983: 252-263).

En 1974, en el marco del reconocimiento de sitios arqueológicos del valle de Ica encargado por el Instituto Nacional de Cultura, Carlos Williams y Miguel Pazos registraron el yacimiento como dos sitios colindantes: Córdova, con el código 10-I03 y el sitio 11-I01, situado inmediatamente 
al suroeste del anterior. Córdova, que representa propiamente el área de los cerros, es descrito en cuatro sectores: «A», ubicado al Sur, es un área compleja compuesta de edificios estucados de índole administrativa o usados como vivienda principal, un patio de 24 por 24 metros y una pequeña pirámide de 14 por 18 metros $^{3}$; «B», en el sureste, es una zona de huacas o pirámides con sectores de viviendas y uso de adobes rectangulares ${ }^{4}$; «C», en el centro del conjunto de cerros, corresponde a un área de cementerio; $\mathrm{y}$ «D», en el noreste del sitio, alberga cementerios paracas (Williams y Pazos 1974). En el sitio 11-I01, encuentran tres montículos dispuestos en «U» que miran hacia el oeste, el central de 70 por 30 metros y dos laterales de 30 por 20 metros, también invadido por viviendas modernas $(\text { ibid. })^{5}$. El material de cerámica asociado pertenece al subestilo Ocucaje 5-6 y 9-10, a Nasca 3 y a Huari (ibid.).

En la década de 1990, durante la prospección dirigida por Anita Cook, Cerro Córdova fue registrado bajo el nombre de Cerro Max Uhle. Ella lo describe como un sitio muy disturbado por el avance de los asentamientos modernos. No obstante, manifiesta que en la cima del cerro se pueden observar restos de muros de adobes y algunos de piedra, y, en la parte inferior, abundantes restos de tejidos pertenecientes a fardos funerarios saqueados, así como fragmentos de cerámica de Ocucaje 8, 9, 10, Nasca Temprano, del Horizonte Medio y del Intermedio Tardío (Cook 1994: 17).

\section{Ubicación y cronología del sitio}

El sitio se ubica en la margen izquierda del río Ica, a unos 400 metros de su cauce y a dos kilómetros al noroeste del pueblo de Ocucaje, en el departamento de Ica. Al igual que Ánimas Altas, Córdova forma parte de la red de establecimientos paracas localizados a lo largo de las dos riberas del río Ica (Fig. 1). Las evidencias arqueológicas se encuentran sobre todas las laderas, las cimas y las depresiones que se ubican dentro de un conjunto de elevaciones rocosas conocidas también como Cerro Córdova, cuyas cumbres alcanzan entre 30 y 33 metros de altura con respecto a la llanura del valle. Este conjunto de cerros es considerado por los lugareńos como si fuera uno solo; visto de planta ocupa un espacio casi oval, con un eje norte-sur de 900 metros y otro de longitud este-oeste de 500 metros. Actualmente, un camino vehicular con proyección de asfaltado corta el sitio en dos partes. Esta ruta une el pueblo de Ocucaje con el asentamiento moderno de Córdova.

Gracias a las descripciones de Uhle en 1901 (Kroeber y Strong 1924: fig. 3; Wurster 1999: 79), sabemos que Cerro Córdova se encontraba rodeado de otros yacimientos arqueológicos denominados sitios B, C, D y F, que también fueron intervenidos por Uhle. En aquel tiempo, el río Ica aún no se encontraba encausado artificialmente en la zona de Ocucaje. A partir de los datos de las prospecciones de Williams y Pazos (1974), y Cook (1994), podemos afirmar que Cerro Córdova ocupaba una posición central con respecto a los otros sitios de la cuenca de Ocucaje. Entre estos yacimientos, sobresalía también Pinilla, ${ }^{6}$ ubicado al este, casi frente a Cerro Córdova, pero en la otra margen del río Ica, el cual ocupa sectores de la pampa que bordea el margen del valle agrícola. Cerro Córdova refleja también un carácter estratégico debido a su topografía elevada, situada en el mismo centro de la llanura de la cuenca. De esta forma, desde el sitio, se podía observar y controlar todo el valle agrícola. Asimismo, su cercanía al cauce del río Ica aseguraba fácil acceso al agua de manera permanente, con lo cual aventaja a otros yacimientos más alejados. Finalmente, su ubicación elevada le aseguraba una defensa natural frente a las inundaciones cíclicas del río Ica.

$\mathrm{Al}$ igual que en la cuenca de Callango, las prospecciones en Ocucaje registraron diversos sitios cuyos materiales revelan ocupaciones culturales sucesivas. En el caso de Cerro Córdova, se ha reconocido vestigios relacionados a las fases Paracas Medio y Tardío, Nasca Temprano y pocas evidencias del Horizonte Medio. Lo mismo se observa en el sitio de Pinilla y en varios establecimientos situados en las pendientes de los cerros que flanquean el valle de Ica en Ocucaje, como Paraya y Cerro Ocucaje, y también en aquellos ubicados en la zona de entrada del río Ica a la cuenca de Ocucaje, así como en los yacimientos reconocidos en las estribaciones de cerro Blanco y la Banda, que limitan el margen oeste del valle de Ica en esta cuenca. Lamentablemente, estos sitios no han 


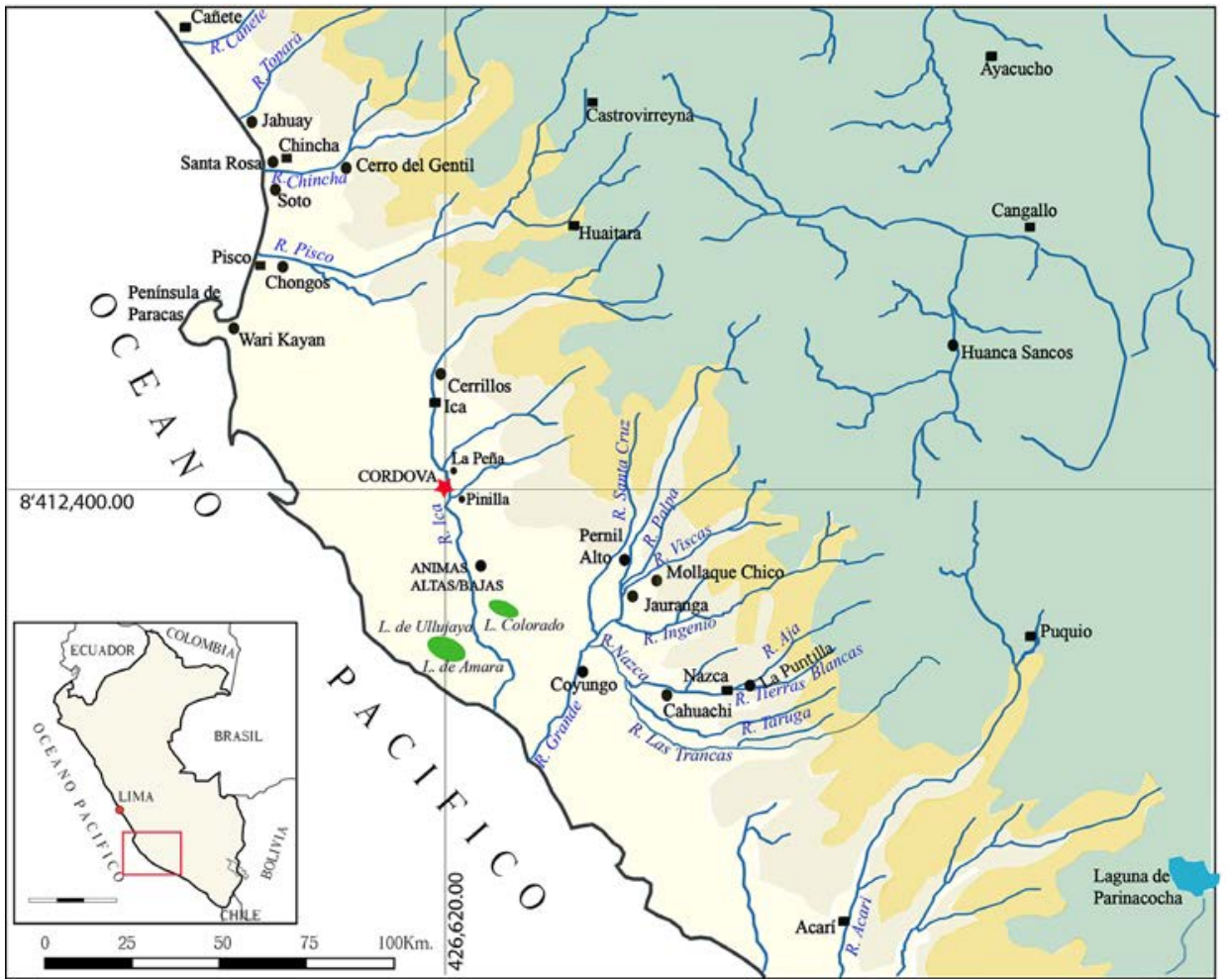

Figura 1. Plano de ubicación de Cerro Córdova (elaboración del mapa: O. D. Llanos J. y A. Bachir Bacha).

sido objeto de excavaciones arqueológicas y hoy están seriamente afectados por el avance urbano y agrícola, así como por la huaquería, por lo cual es muy probable su próxima desaparición.

Pezzia - auspiciado por el Museo Regional de Ica- colectó tres muestras en el sitio de Cerro Córdova. Una de ellas correspondía a materiales de una tumba asociada a cerámica de Ocucaje 9 y arrojó un fechado de $2400+110 \mathrm{BP}(\mathrm{O}-1692)$ que, al ser calibrado al 95, por ciento, da un intervalo de 313 a 206 a.C. (Ziólkowski et al., 1994: 369). Los otros dos fechados corresponden a materiales de la Tumba $P$ asociada a materiales de Nasca 3 y fueron de 2125+110BP (O-1689) y 2014+64BP (P-515), que calibradas respectivamente al 95,4 por ciento caen dentro de los intervalos de 392 a 82 a.C. y 165 a.C. a 120 d.C. (ibid.: 369, 378). Las excavaciones realizadas por los autores en Cerro Córdova no reconocieron cerámica de Ocucaje 8, pero sí aquella definida como Ocucaje 9 y 10, en los estratos situados en los niveles más profundos, separados de los niveles superiores en los que se identificaron materiales de Nasca 1 y Nasca 3. De manera similar a Cerro Córdova, en Ánimas, se ha observado la presencia de materiales de Ocucaje 9 y 10 en los mismos estratos. Un solo sector (Ánimas Bajas) reveló estratos de cerámica de Ocucaje 9/10 separados de los estratos con cerámica de Ocucaje 8 (Bachir Bacha y Llanos 2013).

En Palpa, hay fechados de materiales paracas procedentes de estratos relacionados al estilo Ocucaje 9, que caen dentro del intervalo de 400 a.C. a 200 a.C. (Unkel et al. 2007: 562), aunque hay que señalar que estos materiales han sido datados junto a especímenes de Ocucaje 8 , como si ambos tipos hubiesen sido registrados y colectados en los mismos estratos. No obstante, tomando en cuenta las estratigrafías de distintos sitios Paracas, el estilo Ocucaje 8 se encuentra en niveles diferentes a los del Ócucaje 9. En Ánimas Altas, Cerro Córdova y Jauranga, el material señalado como Ocucaje 9 se encuentra mezclado con el de Ocucaje 10 (ver Isla et al. 2003: 256-257; Bachir Bacha y Llanos 2013: 182-183). Siendo los materiales de Ocucaje 8 más antiguos, es obvio que 
los contextos más tempranos reconocidos en el sector excavado en la zona III de Cerro Córdova, ligados a Ocucaje 9 y 10, son más tardíos. Estos se sitúan en el período de 200 a 150 a.C., mientras que los contextos asociados al estilo Nasca 1, 3-4, se situarían en el intervalo de 100 a.C. a 400 d.C.

\section{El complejo arqueológico Cerro Córdova}

En 2013 y 2014, Bachir Bacha y Llanos realizaron un reconocimiento global del complejo arqueológico, un levantamiento topográfico y dos excavaciones con el objetivo de caracterizar su secuencia ocupacional y comparar su cultura material con aquella de Ánimas para así establecer correspondencias con este yacimiento. Actualmente, Cerro Córdova se encuentra dividido por una carretera, que forma dos bloques (ver Bachir Bacha 2013, 2014). El más importante está situado al oeste y guarda los principales restos arquitectónicos, y fue dividido en cuatro zonas (I, II, III, IV), mientras que el bloque situado al este y que contiene pocos vestigios arquitectónicos fue dividido en dos $(\mathrm{V}, \mathrm{VI})$. Las zonas fueron determinadas sobre la base de los conjuntos de elevaciones separados por las depresiones o especie de quebradas que caracterizan la topografía del lugar (Fig. 2).

La Zona I presenta varias cimas rocosas; la más elevada alcanza 30 metros de altura. En esta área, se observa también un cerro cuya cima se presenta como una meseta a una altura de 33 metros. En ella, se pudo observar un conjunto de tumbas excavadas en la misma roca. Se registraron también diversas plataformas ascendentes, que están asentadas en las pendientes norte y este de la zona; sobre ellas, se registraron restos arquitectónicos de adobes y piedra canteada. Una concentración importante de estas estructuras se encuentra en la pendiente norte. Lamentablemente, esta área ha sido muy huaqueada; no obstante, se ha podido registrar los rellenos monumentales que formaban estas plataformas e igualmente restos de muros de adobes finamente enlucidos. Estas paredes parecen acondicionar pasadizos que conducen hacia las estructuras más elevadas, lastimosamente bastante huaqueadas. Estos datos podrían señalar la existencia de un área residencial de élite. De hecho, se pudo registrar la estructura de una tumba compleja en la base de una de las cimas rocosas.

La Zona II presenta unas cúspides rocosas que alcanzan 17 y 18 metros de altura. A simple vista se observa sobre sus pendientes que miran hacia el oeste, hacia el valle, restos de plataformas que ascienden desde la base hasta las partes altas del cerro, dotadas de estructuras de adobes y piedra canteada.

Las cúspides más elevadas de la Zona III alcanzan 19 y 22 metros de altura sobre el nivel del valle. Las prospecciones permitieron identificar en las pendientes que miran hacia el oeste, conjuntos de terrazas ascendentes y tumbas en las cimas rocosas de esta zona. En las partes bajas, se registraron áreas destinadas a la cocción de cerámica en hornos aéreos caracterizados por sucesivos estratos de combustión, en cuyos perfiles se observan abundantes tiestos de cerámica nasca temprano.

En la Zona IV, se observan diversas cimas que alcanzan 33 metros de altura. Una de las cimas rocosas tiene restos de estructuras y una pequeña meseta con evidencias de arquitectura en adobe. Destaca también un área semiplana, a unos 30 metros sobre el nivel del valle, sobre la cual se reconoció un conjunto arquitectónico complejo formado por muros de adobes. Este conjunto se ubica en el centro de la Zona IV, protegido naturalmente por las elevaciones rocosas. Asimismo, las prospecciones identificaron restos de Spondylus asociados al conjunto citado, testimonio de un espacio vinculado a actividades ceremoniales. Finalmente, sobre las pendientes que miran hacia el este y hacia el sur, se pueden ver restos de plataformas.

\section{Excavación 1 en la Zona II de Cerro Córdova}

Realizada en el 2013 por los autores, la Excavación 1 abarcó la parte media de una de las pendientes de la Zona II, a unos 12 metros de altitud (Fig. 3a). A primera vista, en el área escogida, se observaban restos arquitectónicos muy disturbados, cubiertos por derrumbes y escombros de huaqueo, entre los cuales destacaba una estructura orientada hacia el valle que tenía una fachada con enlucido de barro. 


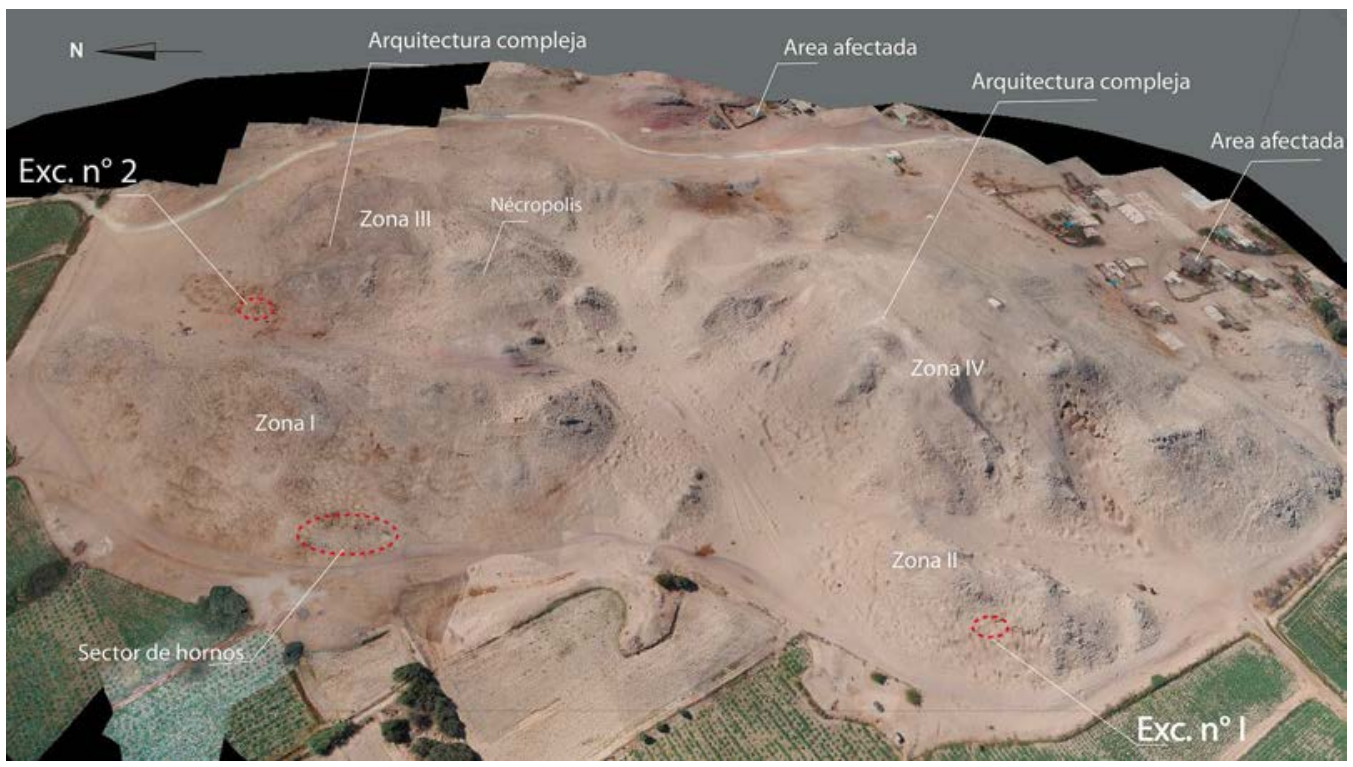

Figura 2. Vista aérea desde el oeste de Cerro Córdova (fotos: Programa Arqueológico Animas Altas, Ica Perú, Arqueosystems).

Cerca de esta se ubicó una unidad de excavación de cinco por cinco metros, que tuvo como objetivo obtener una secuencia estratigráfica a fin de entender la ocupación del lugar y las posibles etapas constructivas. Los resultados de la excavación determinaron dos etapas constructivas bien definidas.

\subsection{La primera etapa constructiva}

La primera etapa fue definida a través de un cateo que aprovechó un forado de huaqueo que había dañado la segunda etapa constructiva (Fig. 4a). En este cateo, se detectó el nivel de un piso (ue 24) de barro construido sobre la roca madre. Este piso se asociaba también a un pequeño muro (ue 25) de orientación este-oeste, hecho con bloques de arcilla y asentado sobre la pendiente rocosa (ue 26). Es difícil entender la arquitectura de este momento sin retirar los estratos que conforman la segunda etapa constructiva. No se encontró material asociado a la arquitectura de esta etapa que permitiera asignarla a alguna fase paracas.

\subsection{La segunda etapa constructiva: Las plataformas}

Esta etapa implicó la planificación del levantamiento de tres plataformas sobre los vestigios de la fase anterior (Figs. 4a y 4b), lo que significó cubrir el piso (ue 24) y el muro (ue 25) con rellenos compactos formados por capas de tierra y otras de vegetales de un grosor de 0,80 metros (ue 20). Este nuevo relleno se extiende hacia el oeste (áreas no excavadas) y forma evidentemente el cuerpo de una primera plataforma. Paralelamente, al este del relleno citado y por encima del área de la pendiente rocosa, se elevó otro relleno formado por paquetes compactos de vegetales $(0,10$ metros de grosor y 1 a 1,5 metros de largo) muy bien apilados unos sobre otros, dispuestos horizontalmente de este a oeste. Este relleno (ue 9) debió alcanzar una altura de 2,5 metros y formaba el cuerpo de una segunda plataforma; sin embargo, actualmente conserva solo 1,80 metros debido a los derrumbes y a la huaquería. Finalmente, una tercera plataforma se eleva al sur de la primera. Está formada por un muro de contención de adobes (ue 6) en dirección este-oeste, situado casi por encima del antiguo muro de la primera etapa constructiva, en el mismo eje. El muro de adobes 

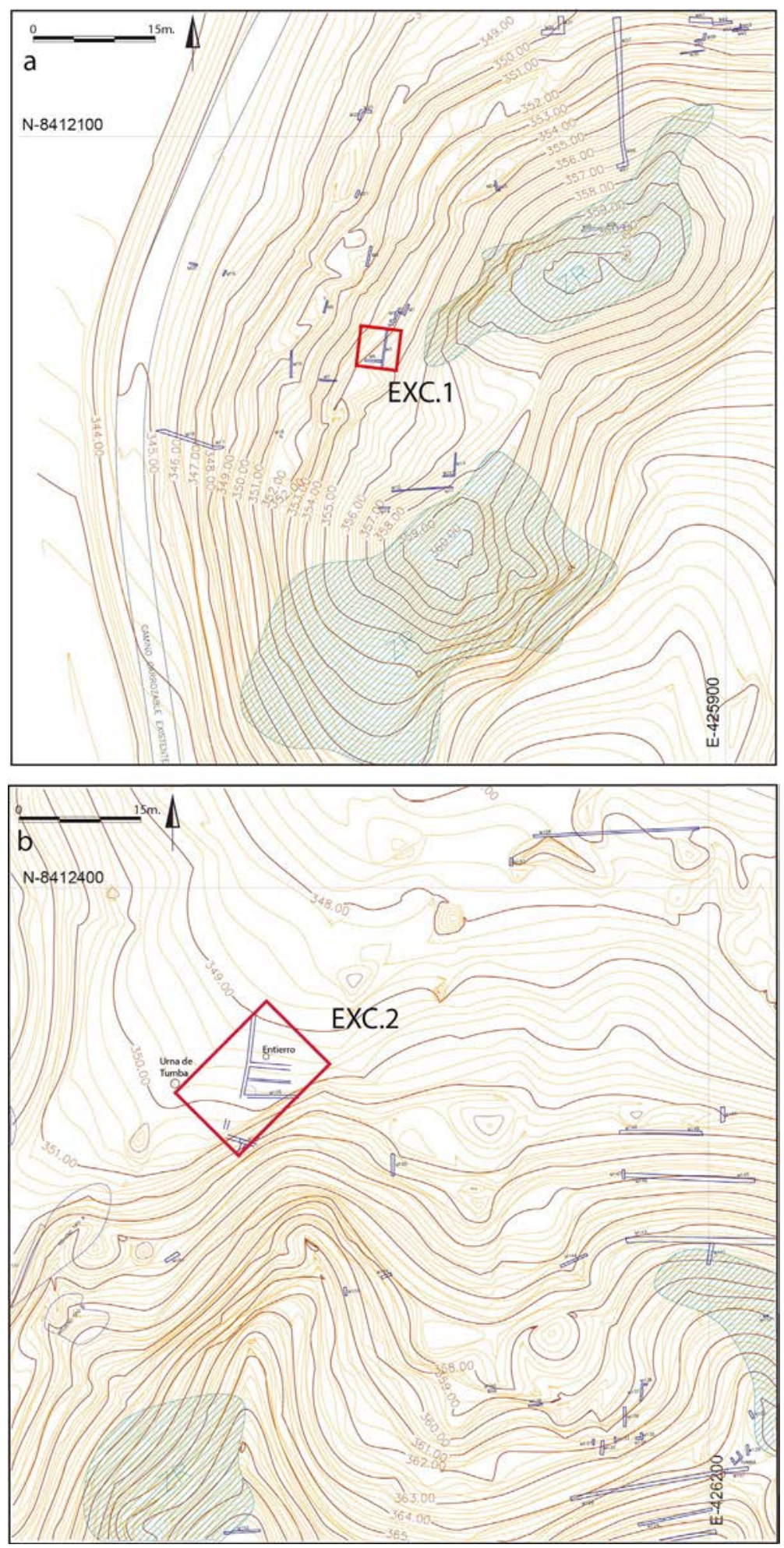

Figura 3. a. Ubicación de la excavación $n^{\circ} 1$ zona II; b. Ubicación de la excavación $n^{\circ} 2$ zona I (elaboración de los planos: R. Rojas, O. D. Llanos J. y A. Bachir Bacha). 


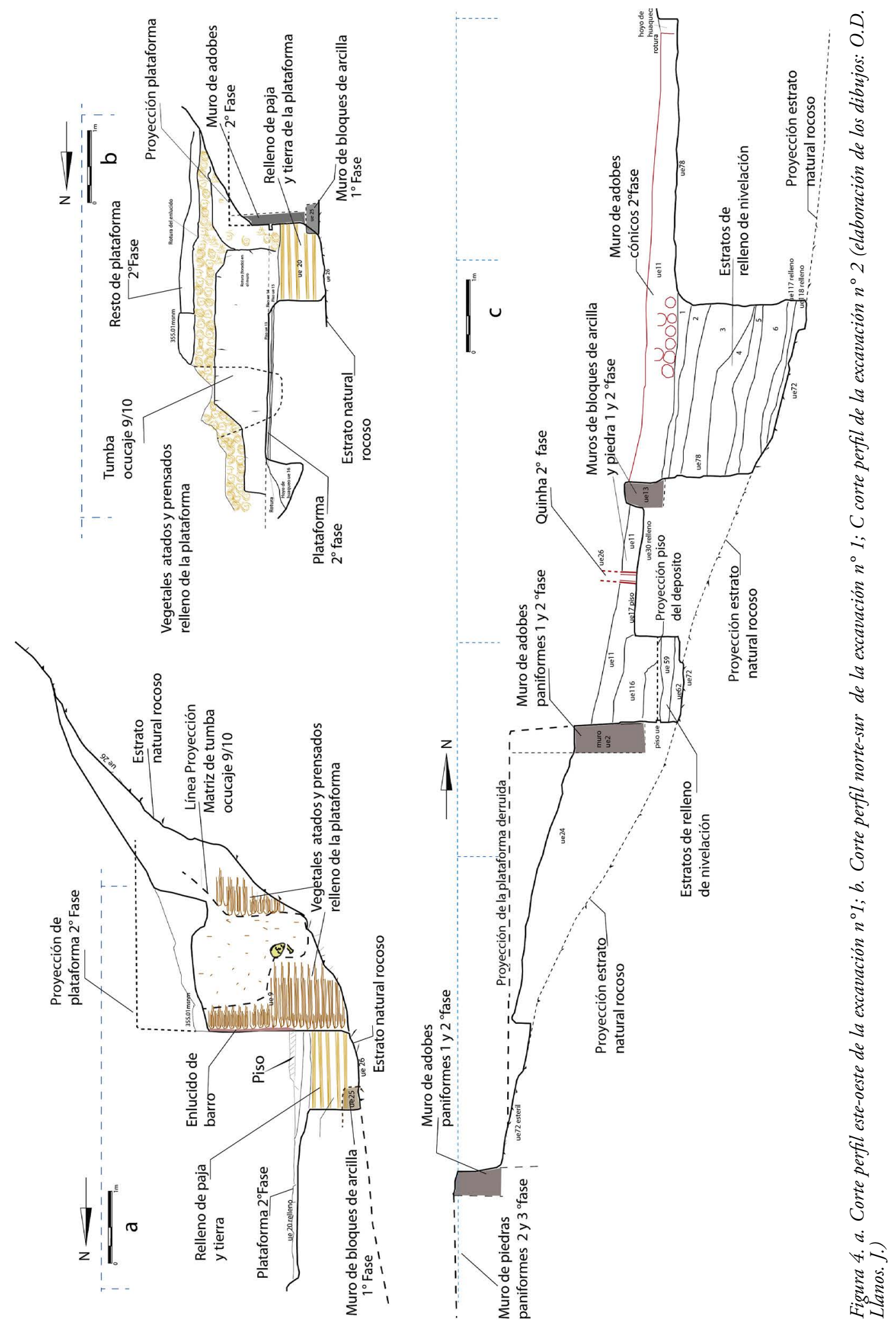


contiene rellenos de vegetales compactos, compuestos por chala de maíz y carrizo, así como capas de tierra y cascajo (ue 19). Esta plataforma alcanzó una altura de casi dos metros y se extiende hacia el sur en áreas no excavadas.

Una vez que se colocaron los rellenos de las plataformas, se inició el acabado de la fachada de la segunda plataforma que mira hacia el oeste, articulada perpendicularmente con la fachada de adobes de la tercera plataforma orientada hacia el norte. Estos dos frontis forman sin duda un recinto ortogonal situado sobre el relleno de la primera plataforma, sobre el cual se construyó un piso de barro (ue 15 y 18). Se pudo igualmente comprobar la existencia de un segundo piso (ue 14) sobre el anterior, lo que nos lleva a pensar en una remodelación. Lamentablemente, estos pisos están ausentes en varias secciones del área excavada debido a la intensa huaquería. Sobre este piso, se elevó otro muro de adobes (ue 17) de orientación norte-sur, que constituyen un muro de división dentro del ambiente.

No fue posible registrar ningún piso de terraza sobre los restos del relleno vegetal de la segunda plataforma debido a los derrumbes y al intenso huaqueo del componente arquitectónico. El evento más importante en este sector está representado por el hallazgo de una tumba dentro del relleno de la segunda plataforma (Figs. 4a, 5a). Si bien estaba saqueada, se observa que la matriz (ue 23) se excavó en los estratos de los rellenos vegetales hasta llegar a la capa natural rocosa, a unos dos metros de profundidad de la superficie de la plataforma.

\subsection{El patrón constructivo}

La primera etapa constructiva se encuentra representada por el muro (ue 25) y su piso (ue 24), ambos levantados sobre la roca natural. El muro fue construido con bloques de arcilla sedimentaria unidos con argamasa de barro. Esta misma técnica aparece en otros sectores de Cerro Córdova, especialmente en las secciones bajas de las pendientes, donde se observan muros de contención de las plataformas. Ellos nos recuerdan los muros de los edificios de Ánimas Altas y otros yacimientos paracas en la cuenca de Callango.

La segunda etapa, relacionada a las tres plataformas citadas, fue posible gracias a la elevación de rellenos arquitectónicos vegetales (Fig. 5a). El relleno de la plataforma situada a menor altura es el más simple: estratos de vegetales (chala de maíz y carrizo) compactos intercalados con estratos de arena gruesa y cascajo, que alcanzan 0,80 metros de altura. Hacia el este y hacia el sur, se elevan las otras dos plataformas. En aquella situada al este de la primera, se registró un relleno bien organizado (ue 9), conformado por paquetes de chala de maíz retorcida, muy bien apilados y compactados, ordenados simétrica y verticalmente desde la base rocosa hasta una altura superior a dos metros. Esta plataforma no contaba con un muro de contención como frontis; la fachada estaba compuesta por la cara vertical del relleno de paquetes vegetales enlucida por una gruesa capa de barro y paja (ue 5). Esta última tiene un grosor de 0,03 a 0,04 metros; posiblemente, tuvo un elucido de barro fino actualmente inexistente y debió dar la impresión de estar formada internamente por un muro de adobes. Dicho frontis se articula perpendicularmente con la fachada de la tercera plataforma. El ángulo formado por ambas fachadas es sin duda la evidencia de la existencia de un recinto. La tercera plataforma se caracteriza por un muro de contención de adobes (ue 6) que retiene un relleno de vegetales (chala de maíz y carrizo) compactados, y capas de arena gruesa y cascajo. El muro de contención tiene 0,25 metros de ancho y debió alcanzar 1,50 metros de alto, aunque ahora está derruido y solo conserva una altura de 0,50 metros, lo que facilita la observación del relleno de vegetales. El tipo de adobe usado para su construcción — denominado paniformees pequeño y alargado, de base semicircular plana, con un alto entre 0,20 y 0,25 metros, y un grosor de 0,15 metros; su color es beige grisáceo y está compuesto por una masa de barro con piedrecillas y pajilla. Para formar el muro, los adobes se colocaron en hileras, sobre su base semicircular y unidos con argamasa de barro con paja, para luego ser revestidos por una capa de barro de 0,02 a 0,03 metros de espesor y posteriormente por un fino enlucido de barro. En la superficie, se encontraron adobes del mismo tipo como resultado de la destrucción del muro por el huaqueo. 

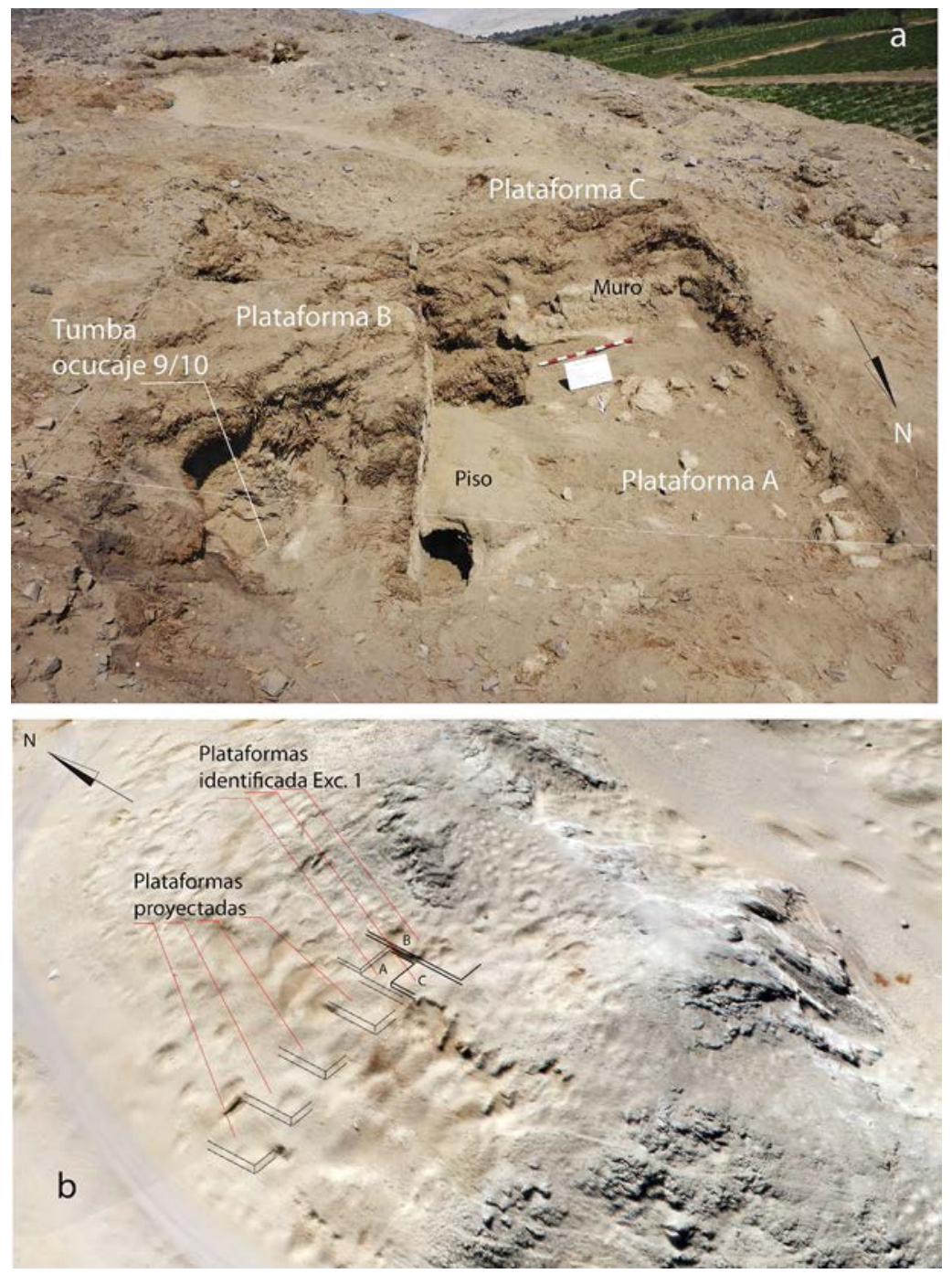

Figura 5. a. Foto desde el norte de la excavación $n^{\circ} 1$ zona; b. Vista aérea del área de la excavación $n^{\circ} 1$ y de la pendiente oeste de la zona II de Cerro Córdova (fotos: Programa Arqueológico Animas Altas, Ica-Perú).

Sobre la terraza de la primera plataforma — cercada por los frontis de la segunda y tercera plataforma-, se ve claramente que el espacio formado sirvió como ambiente. Este espacio tiene pisos de barro bien hechos, que se superponen; estas remodelaciones indican un uso constante del ambiente. Los pisos tienen superficie irregular y están formados por un estrato de arcilla de color gris claro, con incrustaciones de pequeñas piedras, con un espesor variable de 0,03 a 0,04 metros. Estos pisos se articulan a los frontis de la segunda y tercera plataforma. Sobre este espacio, se detectó el resto de otro muro (ue 17), muy deteriorado, con orientación este-oeste, 0,20 metros de ancho y altura actual de 0,15 metros. Al parecer, el muro cumplió una función divisoria dentro del ambiente y debe estar asociado a otros componentes ubicados fuera del área de excavación. Este muro conserva actualmente una sola hilera de adobes del tipo paniforme, con base elíptica, 0,15 metros de altura y 0,20 metros de largo. Antes de iniciar la excavación, se registraron adobes similares en la superficie; ellos habrían formado parte de este muro. 


\subsection{El material asociado}

No se registraron materiales asociados a los elementos arquitectónicos de la primera etapa. En los rellenos utilizados para elevar las dos plataformas del segundo momento constructivo, se registró material cerámico paracas relacionado con la fase Ocucaje 9-10. Asimismo, en la tumba excavada dentro del relleno de la segunda plataforma (Figs. 14a y 14b), se encontraron también algunos fragmentos de Ocucaje 9-10. Por otro lado, se identificaron algunos fragmentos de cerámica de Nasca 3, pero en los niveles superiores que estaban disturbados por la huaquería (Figs. 14g y 14h). En el relleno de la tumba huaqueada, se recuperaron corontas de maíz, restos de algodón, pallares y fragmentos de mate. Así también, se hallaron restos óseos de un individuo adulto y cabello humano, junto a fragmentos de tela llana (algunos de ellos carbonizados), así como un fragmento de cinta con decoración de cara urdimbre y otra cinta bordada, ambas de estilo Paracas y que sin duda pertenecían al difunto. Además de los materiales citados, se registraron restos malacológicos (mejillones, tégulas, choro azul y Mesodesmas), así como huesos de animal (mandíbula de camélido) y cabello humano doblado con pelo de camélido.

\section{Excavación 2 en la Zona III de Cerro Córdova}

Realizada en 2013, la Excavación 2 ocupó un área situada entre la sección plana y el inicio de la pendiente de un cerro que topográficamente sobresale en el sector norte de la Zona III (Fig. 3b). El área escogida se caracterizaba por los restos de un muro que posiblemente era el frontis de una plataforma, además de numerosos escombros y hoyos de huaqueo. Alrededor de este muro, se establecieron seis unidades de excavación; cada una de ellas medía cinco por cinco metros. La excavación tuvo como objetivo entender la arquitectura en las partes bajas de las pendientes, así como identificar una secuencia estratigráfica a partir de la cual se pudiese definir niveles de ocupación y etapas constructivas. Los resultados de la excavación arrojaron tres etapas construcción.

\subsection{La primera etapa constructiva}

Las excavaciones permitieron verificar que, antes de su ocupación, la superficie del cerro era totalmente rocosa y con pendiente aguda, especialmente hacia el lado oeste, donde las excavaciones determinaron una mayor depresión condicionada muy posiblemente por la existencia de una quebrada. La primera etapa representa la fundación del sitio, y, en el área excavada, se refleja en la planificación de los trabajos de nivelación de las secciones inferiores de la pendiente del cerro, y en la gran depresión o especie de quebrada ya citada. Para ello, los paracas instalaron enormes cantidades de relleno conformado por capas de vegetales intercaladas con tierra (ue 59, 78); de este modo, lograron una superficie horizontal que debió extenderse por varias decenas de metros, formando una especie de explanada. Hacia el suroeste de la excavación, se ubicó un relleno similar (ue 38), pero que integraba mucha más tierra, que sobrepasaba los dos metros de profundidad. ${ }^{7}$ Esto señaló la presencia de una gran depresión natural (quebrada) que fue rellenada por los paracas. Así se logró una especie de explanada artificial, sobre la cual se edificaron los espacios arquitectónicos y las plataformas que sirvieron de base a otras que ascienden, adaptándose a la pendiente rocosa del cerro (Fig. 4c).

De esta manera, sobre esos rellenos de nivelación y parte de la pendiente rocosa, se construiría inmediatamente una plataforma ortogonal de dos metros de altura, con cara hacia el norte y el oeste (Figs. 6a, 7a y 7b). La plataforma se eleva gracias a dos muros de contención (ue 2 y ue 134) que forman su frente norte y oeste respectivamente. Estos muros contienen a su vez un relleno de vegetales y de tierra que da volumen de la plataforma (ue 24), sobre la cual se adecuó un piso de barro. En su frontis oeste, se encuentra un acceso (Acceso 1), el cual fue abierto siguiendo un muro perpendicular (ue 114) que ingresa a la estructura. Este muro se asienta en parte sobre el relleno 


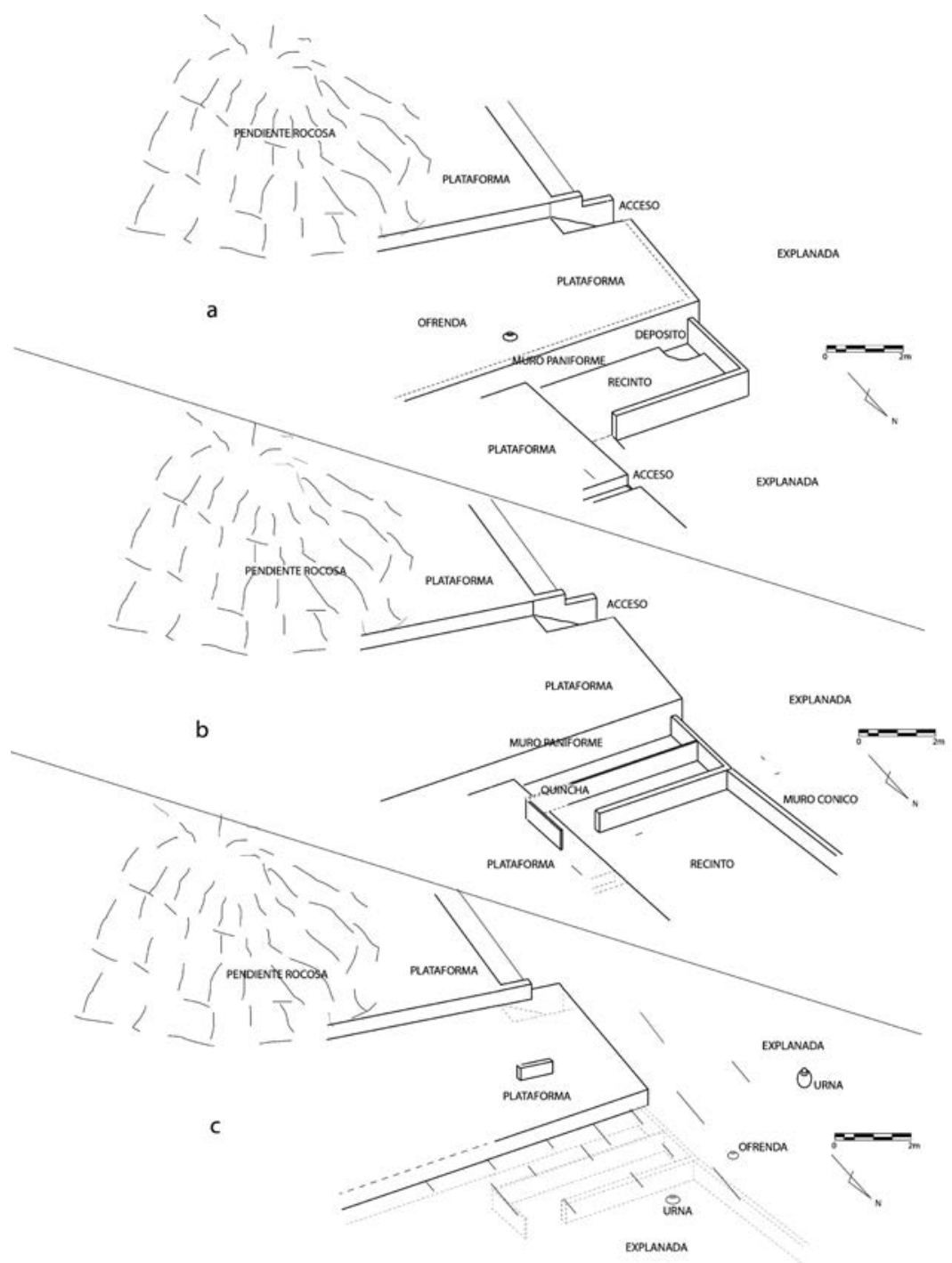

Figura 6. Fases de evolución arquitectónica en sector de la excavación 2, zona II de Córdova (elaboración de los dibujos: O. D. Llanos J.).

vegetal y también sobre la pendiente rocosa, lo cual funciona como muro de una segunda plataforma. El piso de este acceso está en pendiente y reposa igualmente sobre el relleno y la roca del cerro que fue ligeramente tallada, lo cual le da la forma de sinuosas gradas que conducen a la terraza de la primera plataforma. La segunda plataforma, más elevada, se encuentra formada por el muro que delimita el acceso y otro muro lateral hecho con la técnica de la pirca, con piedras canteadas de mediano tamaño. El área de esta plataforma no fue explorada.

Junto a la cara norte de la plataforma, se adecuó un recinto rectangular (Recinto 1) con los muros ue 11 y ue 13. En la esquina suroeste del ambiente, se construyó un depósito semicircular hundido ${ }^{8}$ por debajo del nivel del piso de barro, con una entrada por el muro norte (Acceso 2). Otro vano de acceso, con orientación oeste-este (Acceso 3), fue detectado al noreste del Recinto 1 y está formado por dos muros (ue 41 y ue 42), su apisonado (ue 75) y un peldańo acondicionado con un tronco de huarango. Esta entrada comunica sin duda con otros ambientes situados al este, fuera del área de excavación. 


\subsection{La segunda etapa constructiva o transitoria}

Durante este momento, se realizaron algunas remodelaciones arquitectónicas (Fig. 6b). El área del Recinto 1 fue rediseñada, lo cual afectó el depósito semicircular hundido. Este cambio de la fisonomía arquitectónica pudo dar lugar a dos escenarios en esta segunda etapa: en primer lugar, el depósito del recinto continuó en uso; en segundo lugar, el depósito fue clausurado con un relleno de tierra a fin de obtener un piso nivelado.

Asimismo, el recinto fue dividido por un grueso muro de quincha (ue 26) paralelo al frontis de la plataforma, a partir de lo cual se crearon dos ambientes al interior del Recinto 1. Por otro lado, se elevó un nuevo muro (ue 11a) a manera de prolongación del muro ue 11. Sin embargo, la extensión de este nuevo muro no guarda el mismo eje de orientación que el muro ue 11; varía en unos $5^{\circ}$ hacia el noroeste. Esta pared supera los siete metros de longitud y prolonga hacia el norte, fuera del área excavada. Obviamente, dicho muro funcionaba como el límite oeste de un nuevo recinto (Recinto 2), pero también como estructura de separación con las áreas situadas al oeste, que supuestamente funcionaban como una explanada.

El acceso con peldaño de huarango de la fase anterior aparentemente fue reutilizado, pero también se intuyen remodelaciones en el área hacia donde este desembocaba. Aunque dicho sector estaba muy huaqueado, se registró un muro de quincha (ue 43) similar estructuralmente al muro de quincha ue 26, con el cual formaba una esquina de $90^{\circ}$. En un momento posterior, el acceso con peldaño de huarango fue clausurado y rellenado (ue 35-55), aparentemente para formar una pequeña plataforma o un área en desnivel que se prolonga hacia el este.

En los rellenos de remodelación que clausuraron el depósito (ue 35, 40), así como en los que cerraron el vano de acceso con peldaño de huarango (ue 55), se registraron materiales paracas de estilo Ocucaje 9 y 10 junto con materiales de Nasca 1.

\subsection{La tercera etapa constructiva}

Los niveles estratigráficos de este momento se encuentran muy disturbados (al 85 por ciento); no obstante, se ha logrado determinar que durante él se realizaron una serie de remodelaciones que, por un lado, involucraron la clausura del acceso en el frontis oeste de la plataforma, así como la elevación de los niveles de uso del ambiente de quincha y del Recinto 2 con relleno de tierra (Fig. 6c). Durante esta etapa, se habría introducido en los rellenos urnas funerarias, una en el relleno del Recinto 2 (Fig. 11a) y otra en el área de la explanada al este de la primera plataforma.

Es posible que el muro de la fachada lateral oeste de la primera plataforma - construido con piedras canteadas - haya tenido una mayor altura durante este momento, articulándose a otras estructuras similares en mampostería de piedra. Por otro lado, el ambiente de quincha, así como el Recinto 2, siguieron en uso, puesto que secciones superiores de sus cabeceras se encontraban en niveles cerca de la superficie actual, lo que indica que el tiempo provocó su erosión.

El abandono del sitio es el causante del deterioro de los muros de adobes emplazados en las zonas planas. El clima del desierto, los fuertes vientos o "paracas», así como los eventos cíclicos de lluvias habrían colaborado esencialmente con la erosión de estos muros de barro y con el desmoronamiento de los muros de piedra canteada. Esto puede explicar la gran cantidad de estas piedras dispersas en todas las pendientes, partes planas y bajas de los cerros. A esto se suman las excavaciones clandestinas desde comienzos de siglo XX hasta nuestros días.

\subsection{El patrón constructivo}

Las construcciones en este sector implicaron intensos trabajos de nivelación del terreno rocoso de las pendientes bajas del cerro y de las depresiones naturales que debieron existir en esta área. Esto fue logrado gracias a la colocación de rellenos conformados por capas de tierra que incluían toda clase de desechos culturales y estratos vegetales esencialmente conformados por chala de maíz. Sobre esta nivelación, se levantarían las plataformas que descansan sobre las pendientes, así como 
los ambientes en las secciones planas niveladas. La plataforma intervenida habría superado los dos metros de alto y contaba con una terraza con piso de barro, sobre la cual se registraron los restos de otro muro de adobes, muy derruido, que sin duda eran el paramento de un ambiente hoy inexistente por los efectos de la huaquería.

El material utilizado en la construcción de los muros de contención de la primera plataforma es variable. En la base del muro de la fachada norte, se observa el uso de bloques de arcilla sedimentaria de tamaño mediano ( 0,30 por 0,25 metros), que incluyen en algunas secciones piedras canteadas medianas, todos unidos con argamasa de barro. Sobre este nivel, se siguió levantando el muro con adobes paniformes semialargados, colocados verticalmente en hileras y unidos también con argamasa de barro. Estos adobes tienen 0,25 metros de alto y 0,20 metros de ancho, con base plana semielíptica. Sobre esta mampostería, se aplicó un grueso y tosco enlucido de barro de 0,02 metros de grosor. En cambio, el muro lateral oeste de esta misma plataforma, del cual solo quedan bases muy erosionadas, fue levantado desde sus bases con adobes paniformes alargados, posiblemente similares a los de la sección superior del muro de la fachada norte de esta plataforma.

Como se indicó, se ingresaba a la primera plataforma a través de un acceso abierto en su fachada oeste, cuyo piso aprovechaba el estrato rocoso y estaba flanqueado por un grueso muro de adobes. Esta pared funcionó también como muro de la fachada norte y de contención de rellenos de una segunda plataforma, mientras que otro muro hecho de piedra (pirca), perpendicular al anterior, condicionaba el paramento de contención oeste de esta segunda plataforma. La altura de esta habría superado 1,5 metros por encima de la primera. El muro de la fachada norte de esta segunda plataforma es grueso, mide 0,40 metros de ancho, y se asienta inicialmente sobre el relleno de nivelación y a medida que asciende se asienta sobre la roca del cerro. Fue construido con adobes paniformes alargados, similares a los de la primera plataforma; además, presentaba un enlucido muy similar. La pared de contención oeste de la plataforma se asienta sobre la roca del cerro y tiene un ancho de 0,25 metros, con una altura conservada de 1,30 metros. Fue construida con pequeñas piedras canteadas de 0,10 a 0,15 metros de largo y 0,05 a 0,10 metros de alto, unidas con argamasa de barro y paja.

Los muros que conforman el Recinto 1 fueron levantados con bloques de arcilla sedimentaria que incluía secciones de piedra canteada mediana, todos unidos con argamasa de barro y paja, cubiertos por un revestimiento tosco de barro. El grosor de estos muros es de 0,30 metros y sus alturas son indefinidas. El piso del Recinto 1 fue elaborado con una gruesa capa de barro y presentaba un buen acabado, que se articula con las paredes del depósito hundido que fue ubicado en la esquina suroeste de este ambiente. Este depósito se construyó excavando una parte del relleno de tal forma que sus paredes estuvieron dadas por los perfiles del relleno que fueron revestidos con una fina capa de barro.

Los muretes que conforman el acceso situado al este del Recinto 1 son delgados $(0,15$ y 0,20 metros), con un cimiento de pequeńas piedras canteadas sobre las que se asentaron adobes paniformes de base plana elíptica, con una altura de 0,20 metros y un largo de 0,30 metros, unidos con argamasa de barro y paja. Este acceso tiene una grada conformada por un palo de huarango de 0,13 metros de diámetro.

La segunda etapa se caracteriza por el uso de adobes cónicos de tamaño pequeño, unidos con argamasa de barro y paja, utilizados para levantar un muro que crea un nuevo recinto en el lado norte del Recinto 1 (Figs. 4c, 7c). Dichos adobes fueron colocados en dos hileras paralelas, con las bases circulares hacia el paramento, de tal forma que es posible ver las siluetas circulares en los sectores en los que el enlucido de barro ha colapsado. Estas bases tienen un radio que varía entre 0,15 y 0,20 metros y una altura de 0,13 a 0,18 metros, con el que se logra un muro cuyo ancho era de 0,30 metros.

Corresponden también a esta etapa los restos de dos muros de quincha que formaban la esquina de un nuevo ambiente. De ellos solo quedaban sus bases, con alturas entre 0,10 a 0,20 metros. El mejor conservado divide el Recinto 1 en dos secciones. Estaba constituido por dos hileras paralelas de cañas de carrizo colocadas de manera vertical y con contrafuertes de cañas similares colocados horizontalmente y amarrados a los anteriores con cuerdas de fibra vegetal. Posteriormente, fueron enlucidos por una gruesa y tosca capa de barro; de esta manera, se obtuvo un muro de 0,15 metros. 

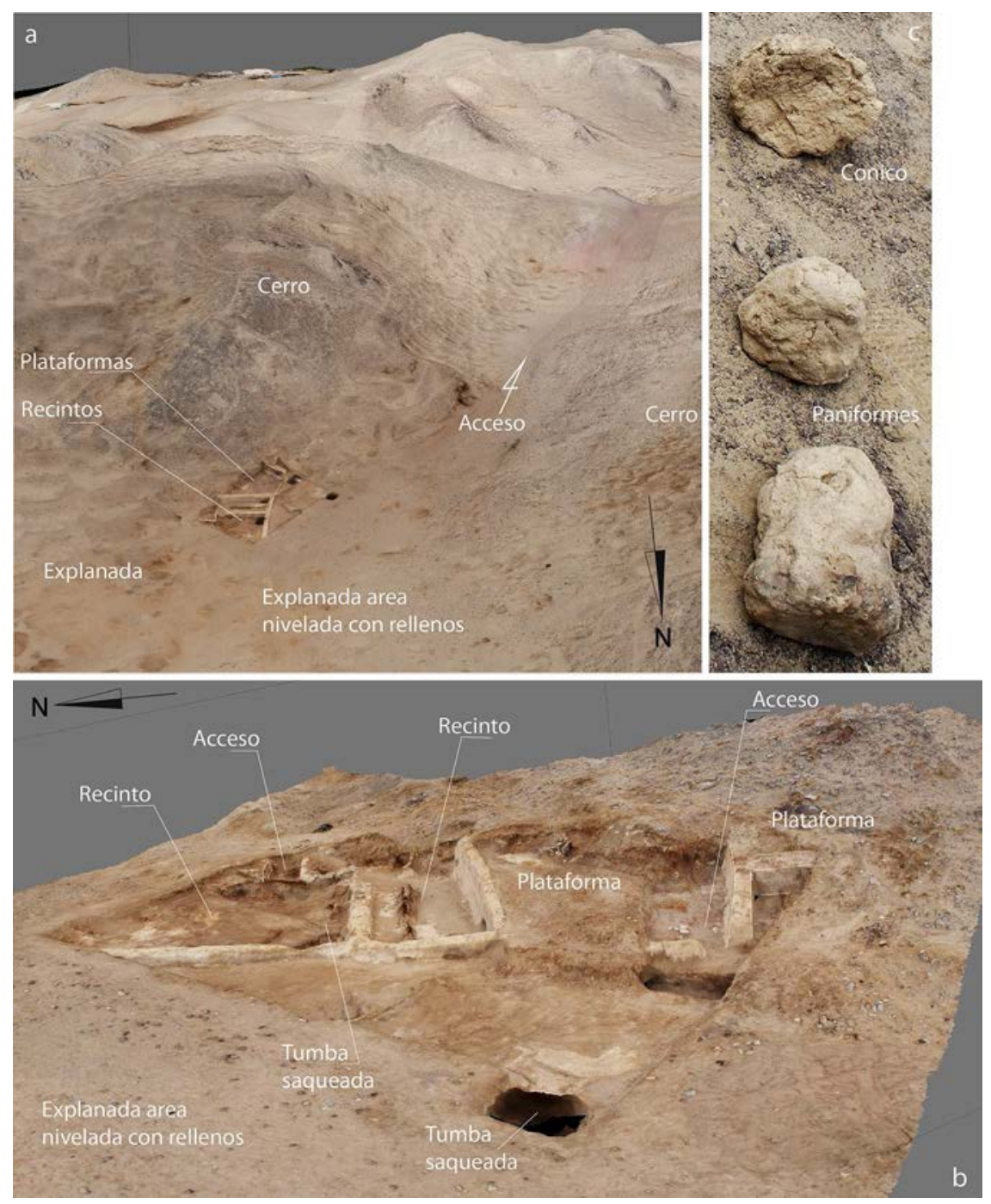

Figura 7. a., b. Vistas desde el norte y el oeste de la excavación $n^{\circ} 2$ en Cerro Córdova; c. Tipos de adobes reconocidos en Cerro Córdova (fotos: Programa Arqueológico Animas Altas, Ica-Perú).

En este sector, la tercera fase habría estado representada por una mayor altura del muro perimétrico oeste, construido con las piedras canteadas de la segunda plataforma, la cual se prolonga hacia el sur, fuera del área excavada. Al parecer, la piedra canteada que se extraía del mismo cerro fue el material constructivo dominante en esta etapa y, con ella, se levantaron diferentes ambientes sobre las plataformas construidas en las etapas anteriores. La gran cantidad de piedras canteadas en la superficie del sitio indican que fue el material empleado en la última etapa de construcción del yacimiento.

\subsection{El material asociado}

Los materiales correspondientes a la primera etapa fueron registrados en los rellenos utilizados para la nivelación del terreno, y en aquellos que dan volumen a la primera y segunda plataforma. Así, en el relleno bajo el piso del depósito del Recinto 1, se colocaron tiestos polícromos de estilo Ocucaje 9-10. En el relleno de la primera plataforma (ue 24), se habrían colocado como posibles ofrendas 

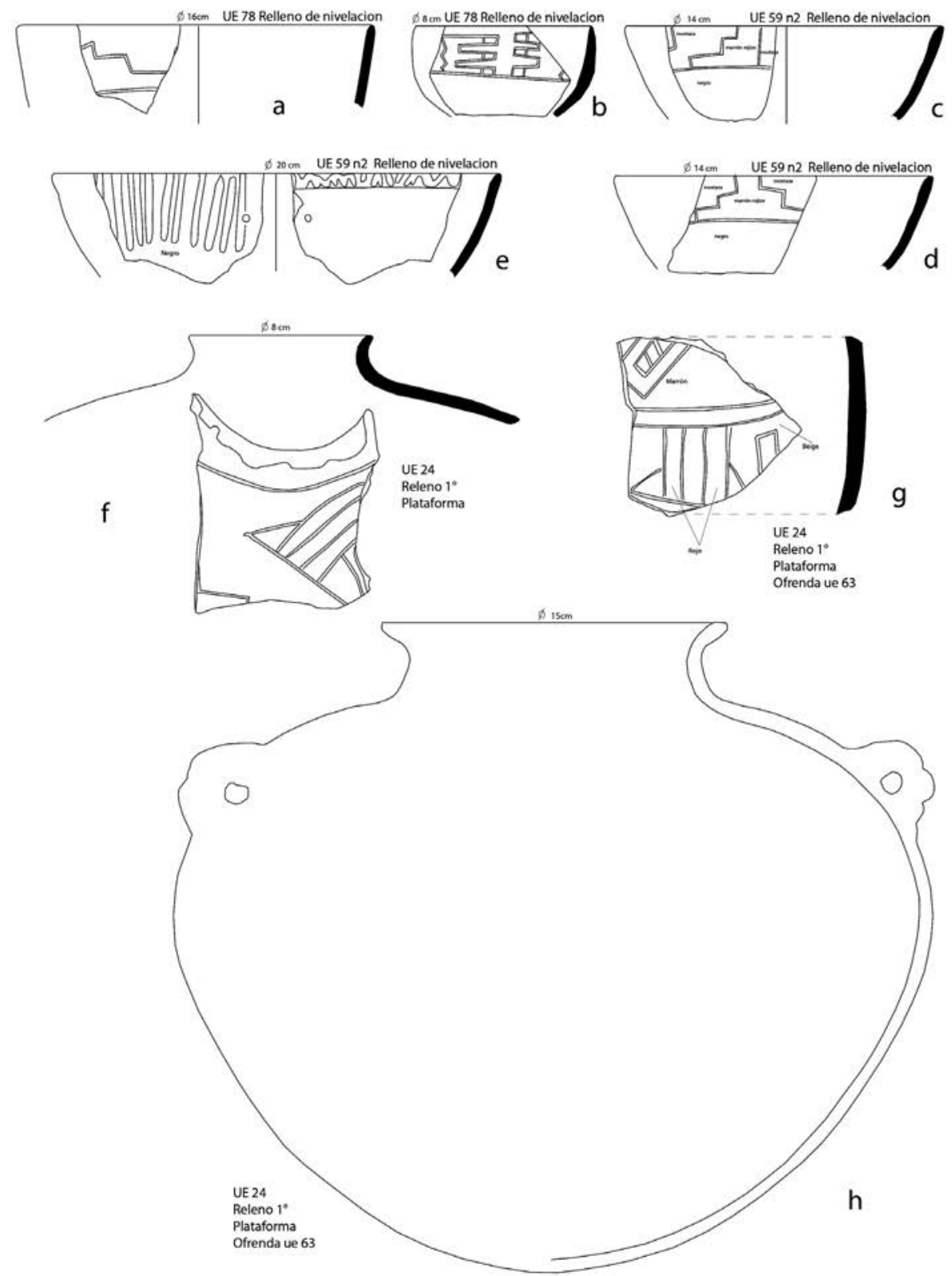

Figura 8. Tipos de cerámica ocucaje 9/10 con decoración incisa reconocida en los primeros estratos arquitectónicos en la Exc. 2, zona I (elaboración de los dibujos: O. D. Llanos J.).

de fundación una olla doméstica de estilo Ocucaje 9 y un fragmento decorado de Ocucaje 9-10, así como fragmentos de textiles con decoración bordada paracas tardío (Figs. 8f-8h; 12e; 11b, 11c; 14n). En los rellenos de nivelación del norte y del oeste de la plataforma, también, se registraron fragmentos de cerámica con decoración polícroma incisa y en negativo ocucaje $9 / 10$, sin presencia de material más tardío (Figs. 8a-8d; 12c, 12d). En el caso del relleno de base del Acceso 3, se depositó una ofrenda constituida por una concha de mar, el fragmento de una paleta de alfarero en madera de huarango y una mota de algodón de color marrón claro y beige. 
Durante el segundo momento, antes del enterramiento y clausura del depósito, se colocó sobre su piso una piel de zorro de color crema grisáceo, cubierta por una capa de barro semicompacta. Junto a ella, se encontraron fragmentos de palitos con hilo, semillas de tomatillo (Lycopersicon pimpinellifolium) y un hueso plano descalcificado, muy pequeño (0,02 a 0,03 metros). En el relleno, se identificaron algunos adobes paniformes y fragmentos de cerámica de Ocucaje 9-10 y ciertos tiestos negros de Nasca 1, algunos con decoración bruñida, logrados bajo cocción reductora.

Antes de la clausura del vano de acceso con palo de huarango, se depositó sobre su piso de barro y paja, a modo de ofrenda, un fragmento de cerámica con decoración incisa y pintura polícroma de Ocucaje 10 con el diseño de un personaje parado de frente (Fig. 12j). En un nivel superior del relleno, se colocó un conjunto de plumas de lechuza de colores blanco, gris y negro sobre una cobertura de motas de algodón blanco, marrón y beige asociada a arena fina. Mientras, en el relleno colindante, que cubre parcialmente el área del Recinto 2, se registraron fragmentos de cerámica ocucaje 9/10 junto con algunos tiestos nasca 1 con decoración negativa.

Los materiales de la tercera etapa se ubican en los rellenos superiores que se habrían acumulado por la continua ocupación. Sin embargo, la mayoría de estos materiales se encuentran disturbados por el huaqueo. Casi junto a la fachada norte de la primera plataforma y en el relleno que cubría el antiguo piso del Recinto 1, se introdujo una ofrenda compuesta por un conjunto de mazorcas de maíz rojo. Junto a la fachada, también se encontró una concentración de hojas de pacae.

En el Recinto 2, se registró el entierro de un infante dentro de una olla de cerámica (Fig. 11a). La olla con el difunto y su ajuar asociado habrían sido introducidos en el relleno por debajo del nivel de uso dicho recinto. Posteriormente, sería muy alterada por la huaquería, que removió al individuo de la vasija, con lo cual quedaron los materiales abandonados en su mismo nivel y dispersos en un radio de dos metros. La olla fue colocada verticalmente; tiene base cóncava y cuerpo globular, con asas en la parte media del cuerpo. Se parece a sus similares de Ocucaje 10 y presentaba gruesas improntas de hollín. Sobre el fondo del recipiente, se ubicó un fragmento de cerámica cortado en forma circular y que aparentemente había cumplido función de tapa. Solo un tiesto con decoración negativa listada se encontró asociado a esta vasija. Los restos de carbón ubicados junto a la vasija indicarían un evento de combustión ligado al enterramiento. Otros materiales recuperados fueron una punta de obsidiana, un hueso largo de animal con huellas de haber sido alisado, fragmentos malacológicos (choro azul, tégula y caracol de loma). Los restos del individuo correspondían a un infante momificado que conservaba parcialmente su mortaja hecha de tejido llano de algodón asociado a restos de hojas de pacae. El fragmento de un batán, otro de un mate, el cuerpo de un ave envuelto en un tejido llano y los restos de un tejido con decoración bordada lineal paracas removidos por la huaquearía — pero dentro del radio del contexto funerario- indican que dichos materiales formaron parte de su ajuar. Un conjunto de hojas fue depositado en el sector norte del Recinto 2; probablemente, son los restos de una cama de ofrenda que fue disturbada.

$\mathrm{Al}$ oeste del Recinto 2, aunque muy cerca del muro construido con adobes cónicos en el área de la explanada, se depositó como ofrenda una olla globular con cuello y asas listadas (Fig. 9g), con una tapa circular de cerámica colocada en su boca. Estaba apoyada en su base y se encontraba a muy poca profundidad, lo que sugiere que fue una ofrenda hecha en una etapa tardía.

En el área de la explanada, a unos siete metros de la fachada oeste de la primera plataforma y rompiendo el relleno de nivelación, se introdujo una gran vasija de cerámica doméstica de color naranja y paredes gruesas (0,02 metros). De ella solo se encontró su base cóncava a unos dos metros de profundidad. Es muy probable que esta vasija haya cumplido la función de urna funeraria (Fig. 7b), pero lamentablemente fue saqueada en tiempos modernos.

Finalmente, la mayoría de tiestos de cerámica registrados en estos niveles corresponden a cuencos de Nasca 1 (Fig. 15), con decoración en técnica negativa, mezclados con fragmentos de Ocucaje 9-10, y algunos tiestos y textiles polícromos de Nasca 3 (Fig. 14g-14l). La presencia de cerámica paracas en estos niveles se debe a las excavaciones clandestinas que sacaron a la superficie materiales más tempranos situados a mayor profundidad. 

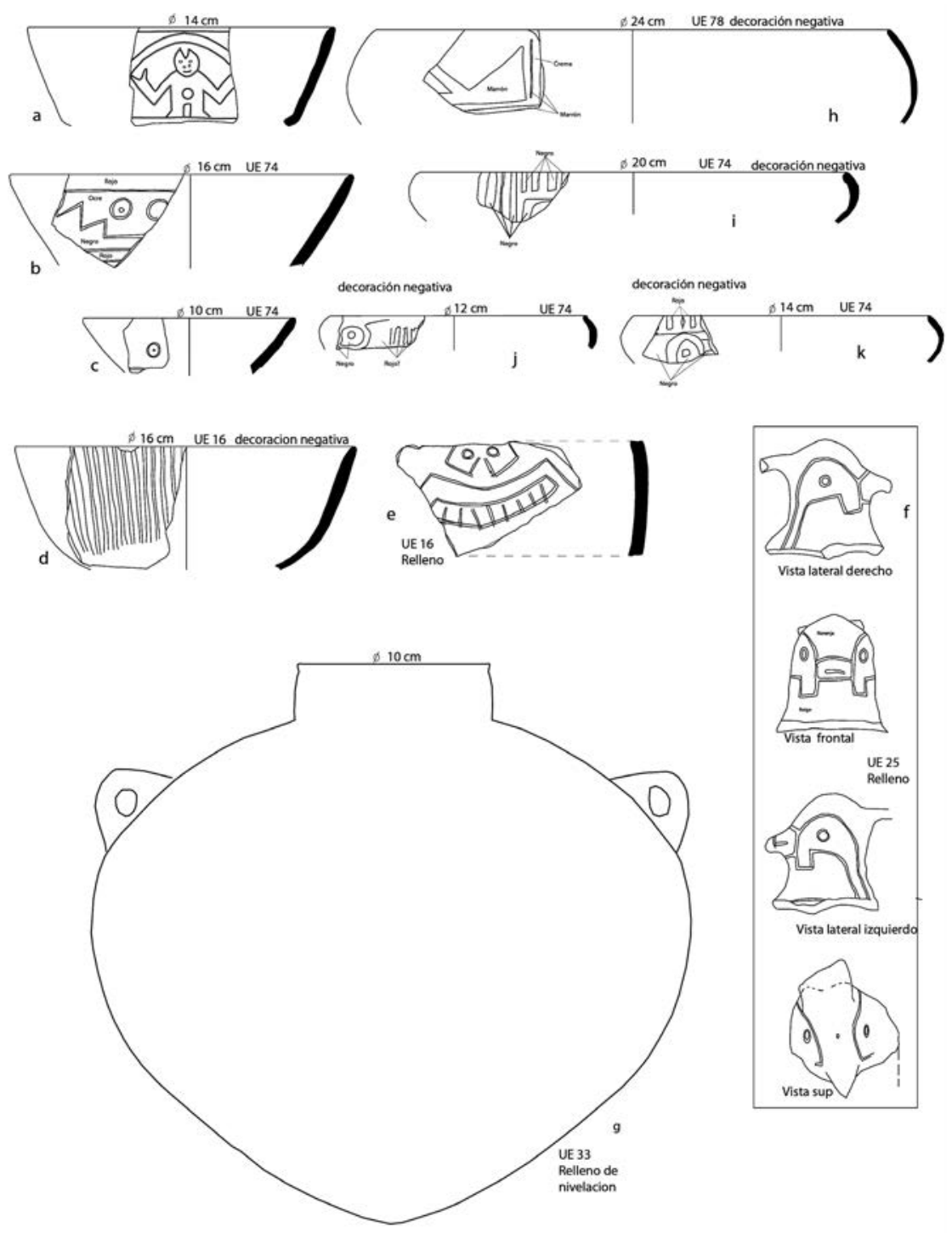

Figura 9. Tipos de cerámica encontrada en los rellenos que cubren la $1^{\circ}$ etapa constructiva de la excavación 2 zona I. a. b. c. d. e. f.g. Tipos de cerámica ocucaje $9 / 10$ con decoración incisa; $h$. i.j. k. Cerámica con decoración negativa de bordes convexos nazcal Cahuachi Red and White Decorated de la excavación 2, zona I (elaboración de los dibujos O. D. Llanos J.).

\section{La función del sitio}

La elección del lugar estaría vinculado con el interés de aprovechar la elevación del cerro para construir sobre él espacios horizontales habitables. Tuvieron así el objetivo de dominar un área proclive a inundaciones cíclicas, debido a su proximidad al cauce del río Ica y, a su vez, para aprovecharlas, puesto que los desbordes convertían los terrenos circundantes en áreas ricas para la actividad agrícola.

Los contextos arquitectónicos definidos en el marco de las últimas excavaciones revelan que el modelo de la plataforma ascendente fue el elemento principal en la planificación arquitectónica. Las plataformas y las nivelaciones modificaron totalmente la topografía de las pendientes rocosas, 
de modo que el paisaje que hoy observamos en Cerro Córdova es prácticamente artificial. Fuera de las cúspides rocosas de los cerros, no existe un área que no haya sido modificada por los rellenos constructivos. Los datos de la excavación interpolados con los de prospección plantean un sistema de terracería sobre todas las pendientes que facilitaba la construcción de estructuras para vivienda y espacios dedicados a la producción.

La elección del lugar tuvo un carácter defensivo frente a las inundaciones, pero también de control y de defensa de las tierras agrícolas frente a posibles invasiones o acciones bélicas. Efectivamente, desde las alturas de Cerro Córdova, se domina visualmente toda la cuenca de Ocucaje y se custodian los ricos terrenos agrícolas. Las grandes cantidades de material vegetal —en particular, la chala de maíz, material privilegiado para construir los rellenos de nivelación o para dar volumen a las plataformasson un indicio del éxito de la infraestructura agrícola desarrollada en torno a Cerro Córdova.

Por otro lado, en ciertos sectores, se observa una arquitectura más compleja, así como un área de enterramiento en la cima de uno de los cerros configurado como una pirámide. La información recogida entre los lugareños indica la existencia de sectores con frisos, ${ }^{9}$ así como tumbas complejas con un rico ajuar funerario que lamentablemente fueron profanadas. ${ }^{10}$ Estos datos plantean la existencia en Cerro Córdova de un cuerpo de élite de la época Paracas, pero también Nasca, que cohabitó con la población campesina, de pescadores y artesanos; de este modo, se pudo inferir que el sitio habría tenido también funciones político administrativas. No obstante, debemos tener presente que las áreas intervenidas arqueológicamente en la Zona I y Zona II tienen carácter doméstico. Ello puede ser explicado por su situación periférica con respecto al núcleo central de Cerro Córdova, a las dimensiones reducidas de los recintos reconocidos, a la evidencia de actividades de almacenaje o de depósito registrada junto a restos de arquitectura de quincha (Excavación II) o al abundante material cerámico de tipo doméstico.

\section{Cerro Córdova: De las interacciones locales paracas a la influencia cultural nasca}

\subsection{Cerro Córdova en la órbita de Ánimas Altas}

Sobre la base de la arquitectura y la cerámica hallada en contextos arqueológicos, la fundación de Cerro Córdova - por lo menos, las áreas exploradas - remonta a la fase Paracas Tardía. Los estratos culturales más profundos excavados en la Zona I y Zona II se encuentran asociados a arquitectura que emplea bloques de arcilla sedimentaria y en algunos casos piedras, pero también adobes. El uso de bloques de arcilla sedimentaria ha sido ampliamente registrado en las estructuras de Ánimas. Al igual que en Ánimas, en Cerro Córdoba, la arquitectura en base de bloques de arcilla se encuentra asociada a cerámica ocucaje 9-10. Estas similitudes indican estrechas relaciones entre las poblaciones de la cuenca de Ocucaje y Callango, e inclusive con las del valle alto de Ica vinculadas al uso de alfares domésticos ocucaje 10 (ver Massey 1992: figs. 5g-5k). Tanto en Cerro Córdova como en Ánimas Altas se observa el uso de vasijas decoradas con el diseño inciso del Ser Oculado, así como otros símbolos también incisos, entre los que destacan escalonados, serpientes, apéndices con terminaciones triangulares, ralladores, así como la presencia de cerámica con diseños listados logrados mediante la técnica del negativo.

No obstante, Ánimas Altas fue abandonado luego de la fase Ocucaje 9-10; asimismo, se percibe un despoblamiento de la cuenca de Callango. En contraposición, Cerro Córdova mantuvo una ocupación estable, al igual que otros sitios de la cuenca de Ocucaje y del valle alto de Ica, cuyos contextos indican una población que comienza a integrar materiales ligados a la tradición simbólica de Nasca (Nasca 1).

\subsection{Cerro Córdova y las interacciones paracas-nasca}

La aparición de alfares nasca 1 en Cerro Córdova (Excavación 2) se encuentra relacionada con la etapa arquitectónica caracterizada por el uso de adobes cónicos (Fig. 4c). Hay que tener en cuenta 


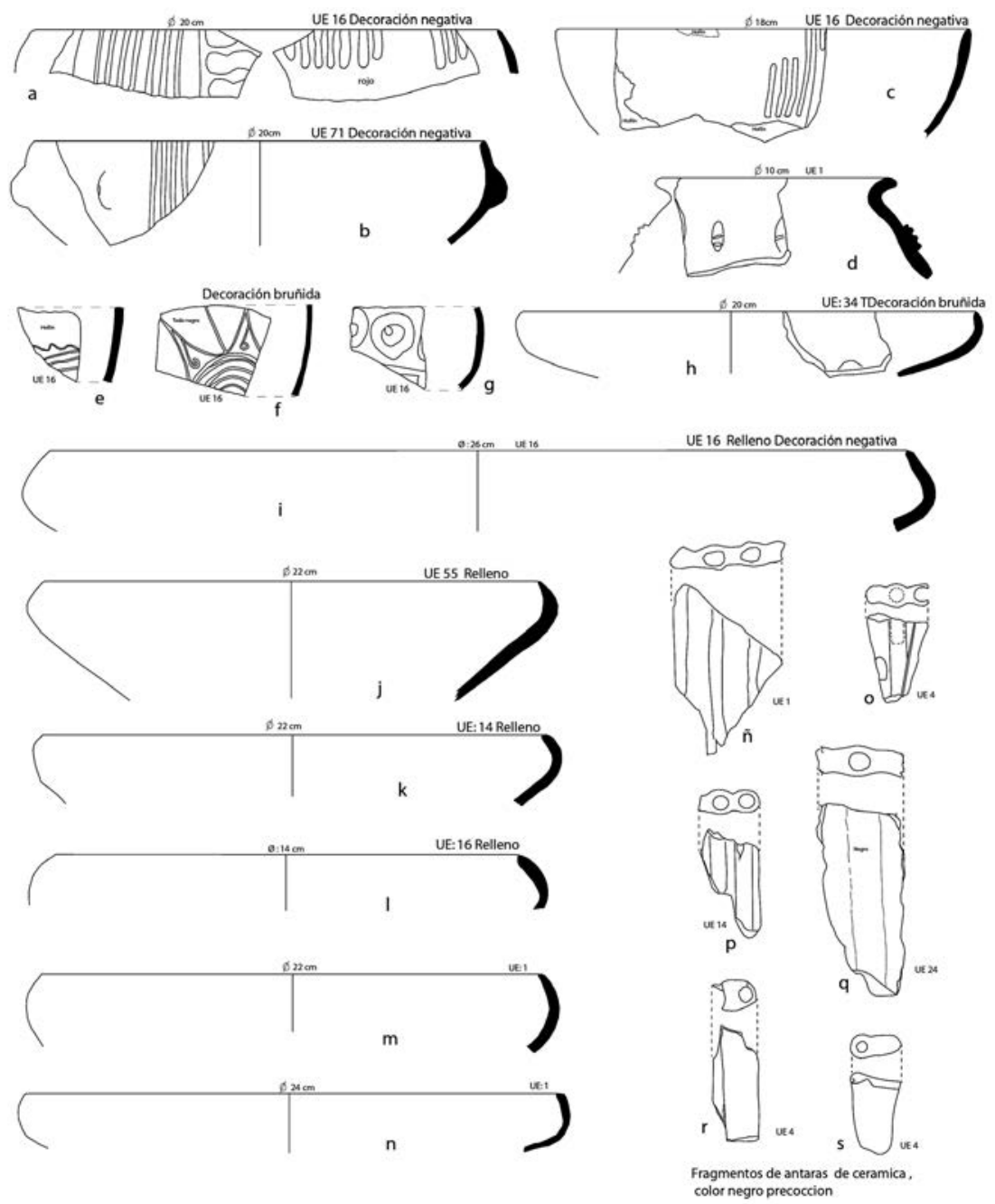

Figura 10. Tipos de cerámica encontrada en los rellenos que cubren la $1^{\circ}$ etapa constructiva de la excavación 2 zona I: a. b. c. Cerámica con decoración negativa tipo nazca 1 Cahuachi Red and White Decorated; d. Cerámica monocroma tipo Cahuachi miscellaneous Modelated and Incised; e. f. g. h. Cahuachi Stylus decorated; i-n. Cuencos convexos negros y antaras negras tipo nazcal logrados bajo cocción reductora; $\tilde{n}$. -s. Fragmentos de antaras de superficies negras, cocción reductora (elaboración de los dibujos $O$. D. Llanos J.).

que este tipo de material de construcción fue muy usado por las poblaciones de la cuenca del río Grande de Nasca desde el Horizonte Temprano, como evoca un contexto funerario asociado a materiales de Cupisnique del sitio de Coyungo (ver Kaulicke et al. 2009: fig. 5). En efecto, los muros de la arquitectura funeraria de Coyungo fueron levantados con adobes cónicos, cuyas bases fueron colocadas hacia el paramento, una técnica arquitectónica utilizada para construir los templos de tradición cupisnique, la que llegó a la región de Nasca pero que al parecer no impactó en el valle de Ica durante el Horizonte Temprano. Esta técnica sería continuada por las poblaciones de Nasca y fue haciéndose aún más compleja, en particular, con el surgimiento del centro político ceremonial de Cahuachi, cuyos primeros edificios fueron levantados con adobes cónicos con la misma disposición y técnica de Cupisnique (Llanos 2009: 98, 195; Orefici 2012: tomo I, 150-155). La arquitectura ceremonial temprana de Cahuachi se encuentra generalmente asociada a cerámica nasca 1 , pero también a escasos materiales paracas. 
Entre los materiales de cerámica eminentemente nasca (Figs. 10e-10g, 14b-14f), se encuentran aquellos de color negro, de paredes finas, confeccionados bajo cocción reductora y con diseños bruñidos o incisos que Strong denominó Cahuachi Stylus decorated y Cahuachi Polished Black incised (1957: figs. 7a, b, c) y que Orefici denominó Nasca 0 (2003: 146). Este tipo también ha sido reconocido en el sitio de La Puntilla, en el valle de Tierras Blancas, asociado a materiales paracas de Ocucaje 10, de su fase Montana (Van Gijseghem 2004: figs. 5.11, 5.12), lo cual lo ubica como una producción nasca muy temprana. No obstante, este alfar es casi inexistente en los principales sitios Paracas del valle de Ica. Efectivamente, las excavaciones de Ánimas Altas/ Ánimas Bajas no revelaron este tipo de cerámica; tampoco, ha sido registrada en el yacimiento de Cerrillos y menos aún en los estratos más profundos reconocidos por nuestras excavaciones en Cerro Córdova. Por tanto, la cerámica negra de cocción reductora, y dotada de decoraciones bruñidas e incisas, no formó parte de la tradición de alfares paracas como lo había planteado Menzel et al. (1964). Alfares nasca 1, entre ellos especímenes negros bruñidos o incisos, solo fueron registrados en los contextos asociados a adobes cónicos documentados por la excavación en la Zona III de Cerro Córdova. A ellos se suma un pequeño porcentaje de fragmentos de antaras negras también confeccionadas con técnica reductora, ${ }^{11}$ (Figs. 10ñ-10s, 14a), objeto musical ausente en los contextos de Ánimas Altas/Ánimas Bajas. ${ }^{12}$ Se conocen igualmente otras muestras de materiales de Nasca 1 recuperados en Ocucaje por las excavaciones clandestinas del hacendado Rubini que caen perfectamente dentro del Cahuachi Stylus Decorated, así como antaras negras de cocción reductora, pero lamentablemente carecen de información sobre los contextos de procedencia (ver Menzel 1971: lam. 6e, lam. 7a, c). Sin duda, todos estos materiales evocan el impacto de la primigenia influencia nasca en el área de Ocucaje.

Otro tipo de cerámica tradicionalmente seńalada como paracas en Cahuachi, y mezclada con cerámica nasca negra bruñida e incisa, es caracterizado por decoración con técnica negativa, denominada por Strong como Cahuachi Red and White Decorated (1957: figs. 8a, c, e; ver también Orefici 2012: tomo I, fig. 12). Strong ilustra igualmente una botella de doble pico y asa puente recolectada durante sus excavaciones en Cahuachi (1957: fig. 7e). Según Silverman, este tipo representa un tercio de la cerámica que Strong consideró como Proto Nasca en sus excavaciones en Cahuachi (Silverman 1992: 37), es decir, Nasca 1. Asimismo, Silverman señala que la variedad descrita es mayoritaria en el corpus Nasca 1 recolectado durante sus excavaciones en Cahuachi (ibid.). Sin embargo, tiestos similares pero sin contexto, provenientes del área de Ocucaje, fueron definidos como Ocucaje 10 por Menzel et al. (1964: fig. 64a), pero como Nasca 1 en el valle alto de Ica por Massey (1992: fig. 6). En las excavaciones de la Zona III de Cerro Córdova, se registraron tiestos similares en los niveles superiores disturbados por la huaquería, junto a fragmentos del tipo Nasca Negro Bruñido, Incisos y Nasca 2, 3 Polícromos (Fig. 13 c, e, f, g, i). Asociados a estos tipos de cerámica estarían los que Strong catalogó como Cahuachi Negative (1957: figs. 6f-j) y Cahuachi Miscellaneous Modelated and Incised (ibid.: fig. 12e-h): el primero, un tipo de cerámica con decoración negativa con fondo oscuro negruzco; y el segundo, un tipo de cerámica monocroma con aplicaciones e incisiones, ambos también registrados en la excavación de la Zona III en Cerro Córdova (Figs. 10d; 13a, 13b, 13d, 13h, 13j).

\subsection{Cerro Córdova y el colapso de Ánimas}

Los contextos reconocidos en Cerro Córdova plantean en un primer momento una coetaneidad con el yacimiento de Ánimas Altas/Ánimas Bajas debido al uso de la cerámica ocucaje 9-10, pero luego - durante el proceso de aparición de la cerámica nasca 1 en Cerro Córdova - se observa un desfase entre ambos sitios. En efecto, a partir de ese momento, Ánimas Altas/ Ánimas Bajas sería abandonado, en tanto que Cerro Córdova mantendría una ocupación estable hasta la fase Nasca 3.

En el caso de Callango, habría que preguntarse por qué Ánimas Altas no fue ocupada durante este momento mientras que Cerro Córdova fue ocupado continuamente. Las prospecciones efectuadas en la cuenca de Callango por Bachir Bacha y Llanos en 2013 y 2014 no revelaron sitios asociados a material nasca 1 , sino de la fase Nasca 3, representada por varios cementerios y yacimientos 

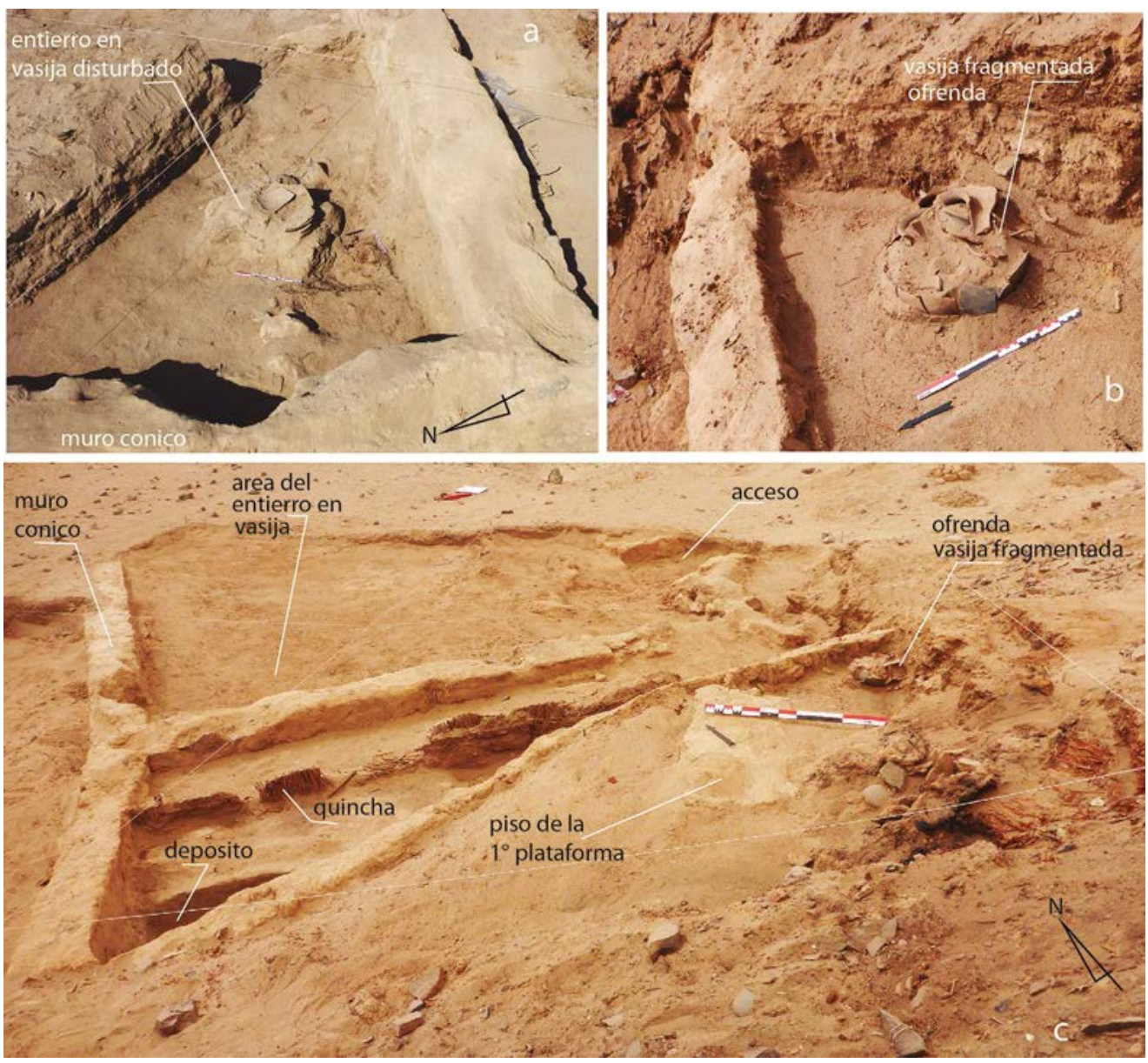

Figura 11. a. Restos del entierro de un infante en olla, depositado en el relleno tardio de la tercera etapa; $b$. Vista del contexto de una olla depositada como ofrenda de fundación en el relleno de la primera plataforma; $c$. Vista general desde la cima de la primera plataforma de la olla depositada como ofrenda de fundación asi como de los espacios arquitectónicos situados adyacentemente la base de la plataforma (fotos: Programa Arqueológico Animas Altas, Ica-Perú)

de pequeña envergadura. Especímenes de Nasca 1 tampoco fueron detectados en Ánimas Altas/ Ánimas Bajas, donde tan solo se registraron de manera aislada algunos tiestos nasca 3. La ausencia de materiales nasca 1 en la cuenca de Callango y en Ánimas Altas/Ánimas Bajas plantea sin duda una coyuntura de abandono del sitio y la cuenca. El despoblamiento del antiguo foco paracas revelaría el colapso de las élites paracas de Callango, lo que implica la desestructuración de la antigua tradición político-religiosa paracas, expresada en su simbología tradicional. La información disponible señala que la población de este importante asentamiento paracas se dispersó en la misma cuenca o migró hacia otros sectores del valle de Ica, posiblemente, hacia Ocucaje. El desprestigio de las antiguas élites paracas y, por ende, la pérdida de mecanismos de materialización de su poder en todo el valle de Ica son condiciones que explican el posterior proceso de readaptación de las poblaciones paracas del valle de Ica hacia los cánones político-culturales nasca en expansión.

Se ha sugerido que la caída de Ánimas Altas se debió a una conquista militar (Massey 1990: 150), pero ello no concuerda con que la mayoría de sus principales edificios fuesen clausurados por rellenos e inmediatamente se elevaran sobre ellos estructuras menos complejas. Tales eventos fueron sin duda efectuados por los mismos paracas en un tiempo muy corto, puesto que los materiales 

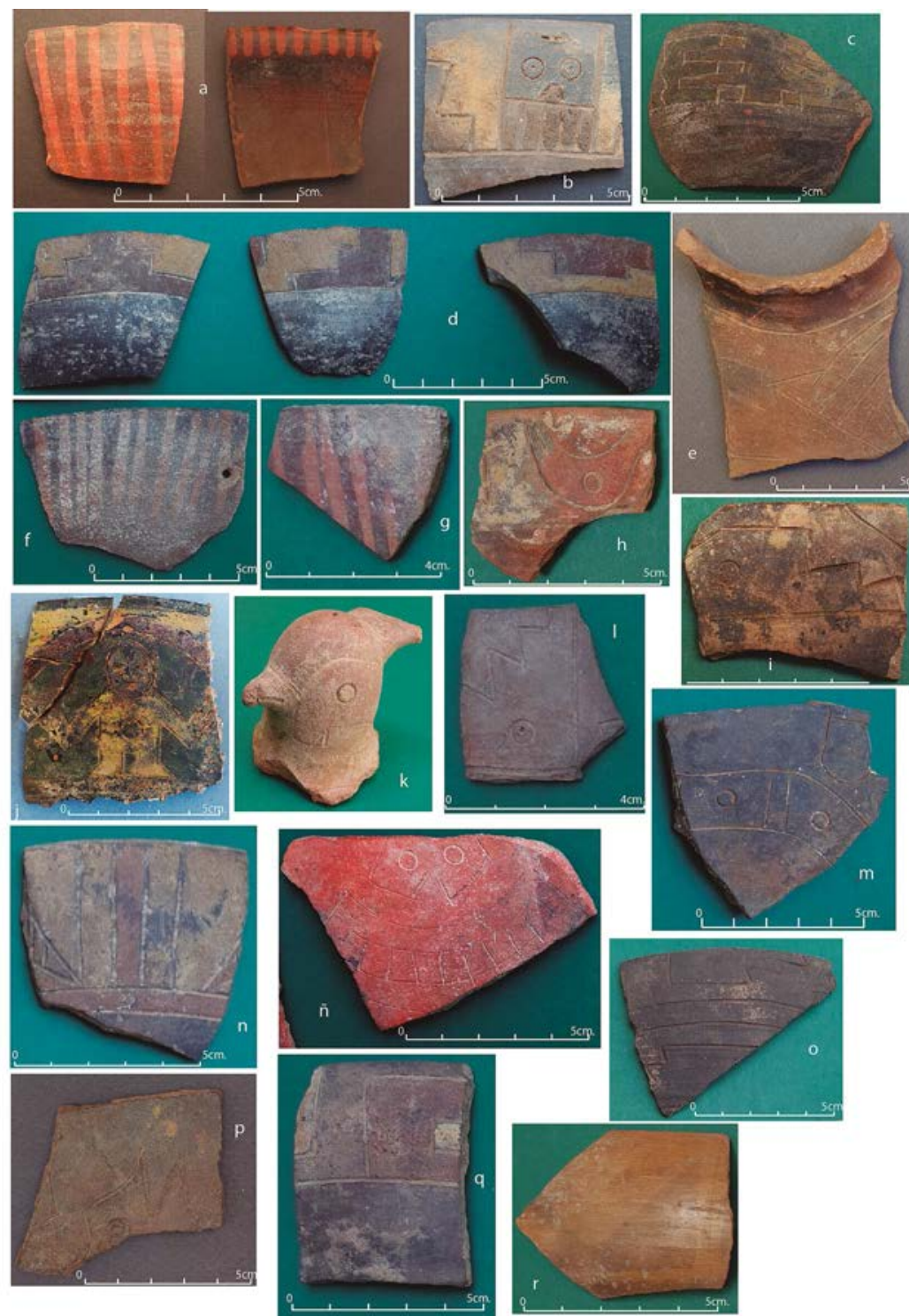

Figura 12. a-b. Tipos de cerámica paracas registradas en la excavación 1 zona II; c. d. e. f. Tipos de cerámica paracas registrados en los rellenos de nivelación de la excavación 2 zona I de la $1^{\circ}$ etapa constructiva; g. h. i. j. k. l. r. Tipos de cerámica paracas con decoración incisa registrados en los rellenos que cubren la $1^{\circ}$ etapa constructiva en la excavación 2 zona I (fotos: O. D. Llanos J. y A. Bachir Bacha).

reconocidos en esos rellenos de clausura pertenecen mayoritariamente a la fase Ocucaje 9-10 y son similares a aquellos reconocidos en los rellenos de los edificios de las primeras fases del sector de Ánimas Altas. Las evidencias de la presencia nasca en el valle de Ica, y especialmente en Ocucaje, no tienen que ser vistas como el efecto de una invasión o de una conquista nazquense. Si bien es cierto la iconografía paracas de la fase Ocucaje 9-10 — tanto en cerámica, textiles, como en los frisos de Ánimas Altas/Ánimas Bajas- evocan personajes o divinidades que portan cuchillos y cabezas trofeo (entre ellos el «Ser Oculado»), estos no deben interpretarse como evocación de conflictos o una situación de guerra interregional. Por el contrario, dicha simbología evoca la materialización del poder político religioso de las élites paracas determinadas a normalizar y a cohesionar a las 
poblaciones dispersas en el valle de Ica, especialmente, desde la fase Ocucaje 8. Estos parámetros simbólicos estructuraban a la entidad política paracas, a la cual quedaron sujetas e identificadas segmentariamente diversas poblaciones del valle de Ica, Pisco, el litoral de Ica e incluso grupos instalados en territorios situados en los valles al norte de la cuenca del río Grande de Nasca, como Palpa y Vizcas. La principal población externa y vecina eran los nasca, que en el proceso histórico de interacciones regionales se convirtieron en sus principales competidores y rivales.

Antes de las excavaciones en Ánimas Altas/Ánimas Bajas, los reportes indicaban la presencia de numerosas puntas de proyectil de obsidiana. ${ }^{13}$ Estos objetos estarían de alguna forma relacionados al simbolismo evocado en uno de los frisos paracas situados en el Montículo 1 y el Montículo 71 en el sector de Ánimas Altas y que estuvieron ligados al enterramiento de personajes de élite (Bachir Bacha y Llanos 2011, 2013). En estos frisos, se puede observar un personaje que porta un cuchillo y una lanza que brota de su mentón —-Montículo 71- (Bachir Bacha y Llanos 2013: fig. 21b) y otro de apariencia helíaca, del cual brotan lanzas —Montículo 1- (ver Massey 1990: fig. 116; Bachir Bacha y Llanos 2013: fig. 28d), pero también personajes mitológicos antropomorfos que portan vegetales (ibid.). Su ubicación como parte de estructuras funerarias de élite relaciona a esta clase social con el monopolio de la violencia política y, a la vez, con el éxito agrícola. Por ello, es muy posible que el área de Ánimas Altas/Ánimas Bajas — principal centro político ceremonial paracas - fuera el espacio idóneo para el desarrollo cíclico de combates rituales, lo que explicaría la abundancia de puntas de proyectiles, así como el simbolismo de los frisos reconocidos en ese sitio. En efecto, en el mundo andino, el combate ritual o tinkuy es concebido como un acto de ofrendar sangre o donar a través del sacrificio la energía vital del vencido (camac) a la naturaleza, con lo cual se asegura la fertilidad agrícola y, por tanto, el bienestar de la comunidad (Llanos 2009: 253). En esa perspectiva, el éxito agrícola dependía de la violencia ceremonial y, por este motivo, dicho éxito se relacionaba míticamente con las élites de Ánimas Altas, puesto que ellas gestionaban dichos enfrentamientos en su núcleo territorial de poder. En otras palabras, las élites detentaban el monopolio de la violencia y, mientras este fuera exitoso, las mismas eran prestigiosas.

Entonces, el colapso y abandono del centro político ceremonial obedecería a factores externos, entre ellos, el impacto de los cambios climáticos que desestabilizaron la estructura de poder político segmentario de toda la esfera paracas, cuyo centro era precisamente Ánimas Altas/Ánimas Bajas. En efecto, las investigaciones en el valle de Palpa han determinado que a mediados del 100 a.C. -fecha que marca el final de la fase Ocucaje 9-10 y los inicios de Nasca- se acentúa el proceso de sequedad de los valles de la vertiente del Pacífico, con un retroceso de la vegetación (Isla 2005). Los efectos de las sequías habrían repercutido en la economía agrícola de Callango y, por ende, en Ánimas Altas/Ánimas Bajas, situado a 1,5 kilómetros del cauce del río Ica. En contraste, esta coyuntura parece no haber afectado a los establecimientos paracas de la cuenca de Ocucaje, entre ellos, Cerro Córdova, que, emplazado en una zona estratégica, muy cerca del cauce del río Ica y con agua todo el año, debió ir ganando mayor importancia.

No obstante, las élites paracas de Ocucaje fueron incapaces de dotarse de nueva infraestructura político-religiosa que continuase con la línea tradicional paracas. Esto se debería a las rivalidades ya existentes entre los diversos grupos paracas locales frente al poder ejercido por las élites de Ánimas Altas, ahora en colapso. De esta forma, y desde una perspectiva de los intereses políticos de Ocucaje, mantener la línea tradicional paracas era como revivir el aura de desprestigio de la otrora élite de Ánimas Altas/Ánimas Bajas. Esto pudo condicionar que las poblaciones de Ocucaje, y entre ellas la de Cerro Córdova, optaran por abrazar los patrones político-religiosos de Nasca, que en ese momento comenzaban a difundirse desde el centro político religioso de Cahuachi. Así, la explicación para la extinción del antiguo modelo político religioso paracas debe buscarse en las ansias de autonomía de los otros grupos locales paracas frente al poder de las élites de Ánimas Altas/ Ánimas Bajas. La agonía del antiguo modelo tradicional paracas debe ser entendido, más bien, como un proceso de readaptación llevado a cabo por las élites paracas enfrentadas a las de Ánimas Altas/Ánimas Bajas, entre las cuales destacarían aquellas de la cuenca de Ocucaje. Finalmente, este proceso de readaptación al modelo político-religioso nasca buscaba sin duda mantener la antigua 

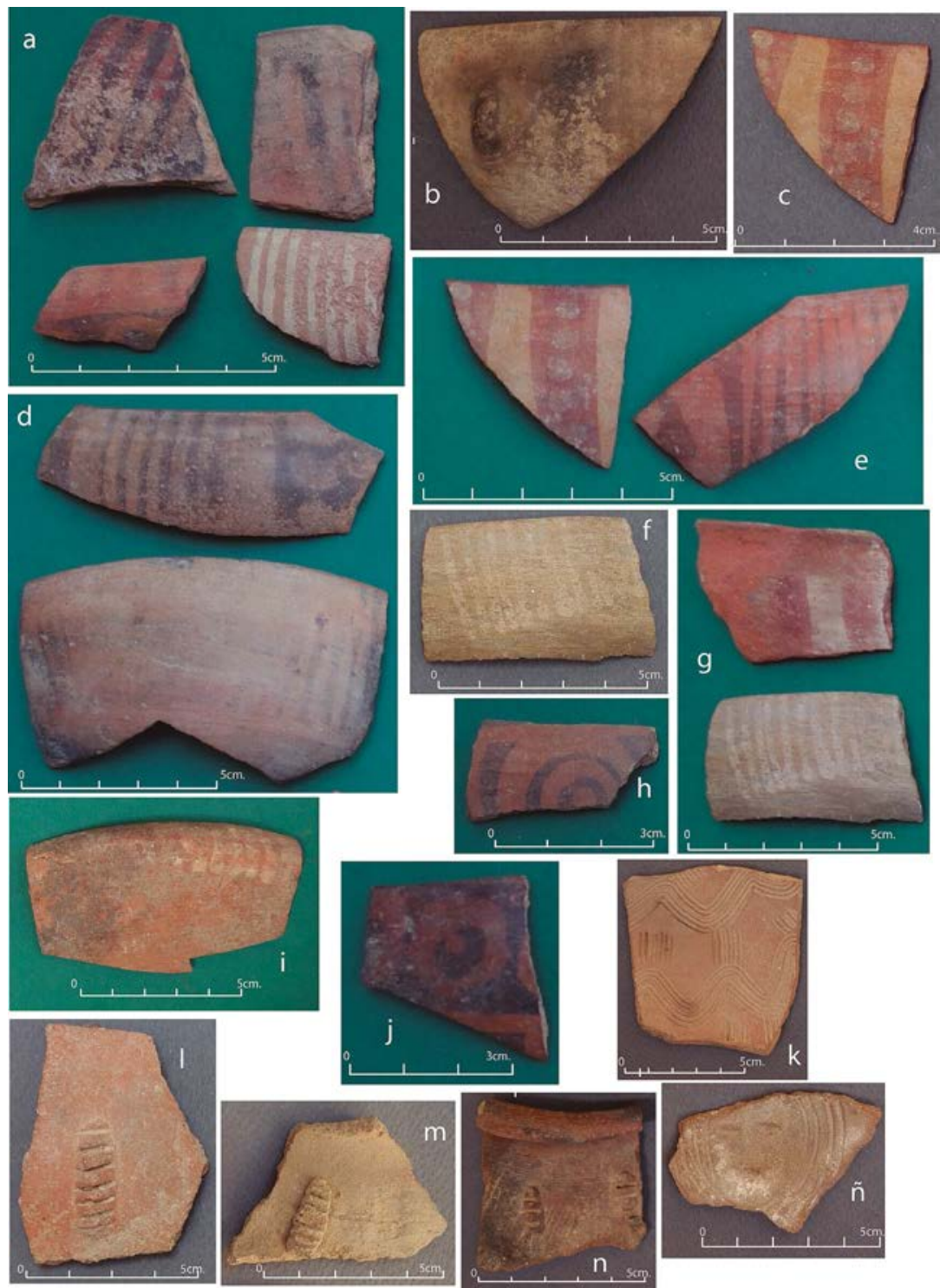

Figura 13. Tipos de cerámica registrada en los niveles que cubren la $1^{\circ}$ etapa constructiva en la excavación 2 zona II: a.b.c.d.e.f.g.h.i.j.k. Tipos de cerámica nazca 1 con decoración negativa registrada; l.m.n. Tipos de cerámica nazca 1 Cabuachi miscellaneous Modelated and Incised; ñ.o. Fragmentos con decoración incisa de tipo paracas tardio (fotos: O. D. Llanos J. y A. Bachir Bacha).

gestión de sus territorios, así como de sus potestades en el valle de Ica y, a la vez, impedir el resurgimiento del poder de las élites de Ánimas. Esta perspectiva explicaría el abandono de Ánimas Altas/ Ánimas Bajas, la reticencia a ocuparlo en épocas posteriores, la rápida propagación de la influencia nasca en el valle de Ica y la subsecuente continuidad ocupacional de la cuenca de Ocucaje, dentro de la cual el establecimiento de Cerro Córdova parece haber cumplido un rol de primer orden, que facilitó la expansión de la influencia político-religiosa nasca en el valle de Ica. 


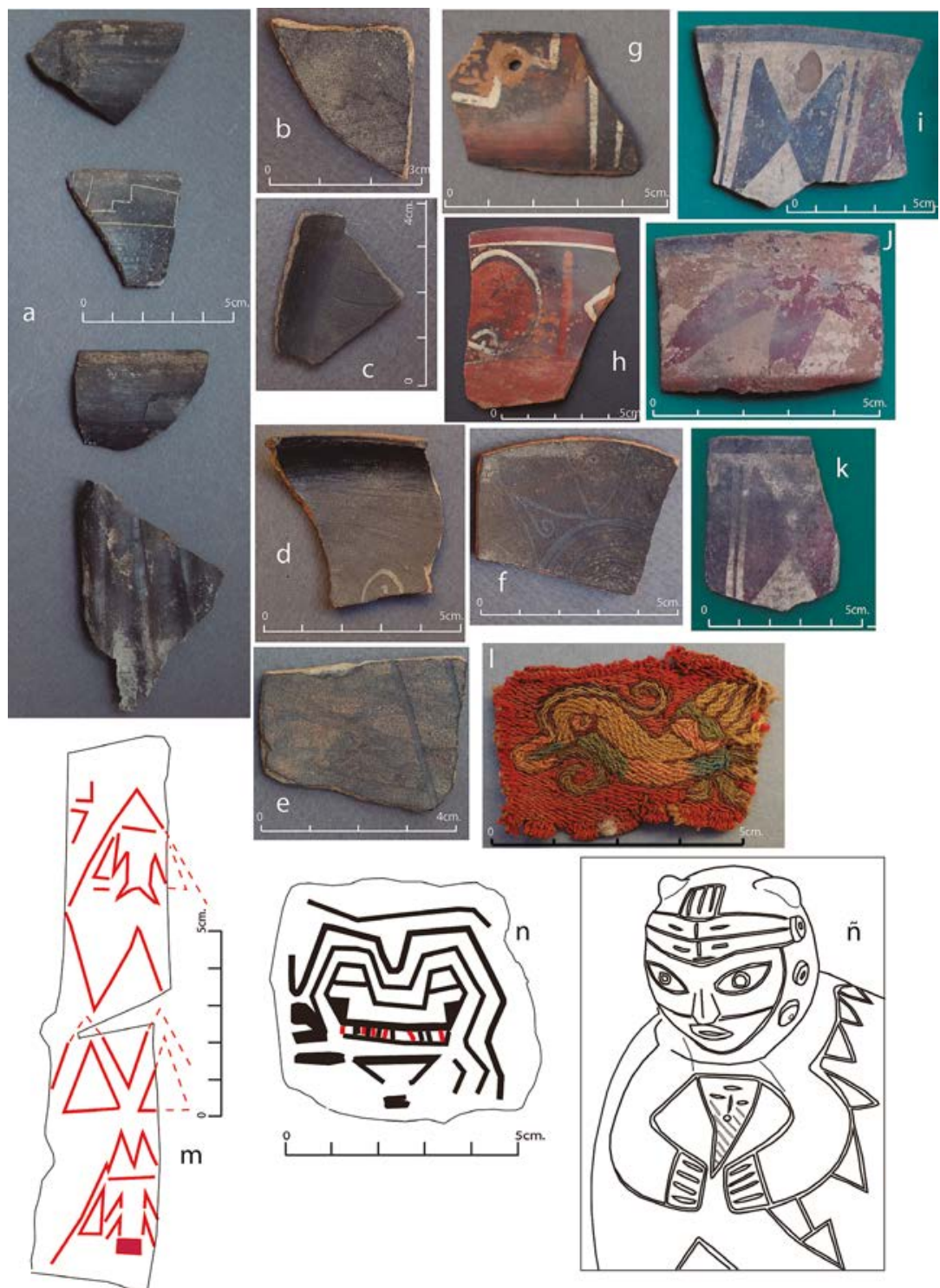

Figura 14. Materiales de estilo nazca registrados en los rellenos superiores en la excavaciones 1 y 2: a.f. Cerámica nazca Cahuachi Stylus Decorated y Cahuachi Polished Black incised; $g$-h. Cerámica nazca 3 de la excavación 1 zona II; i-k. Cerámica nazca 3 de la excavación 2 zona I. l. Fragmento de textil nazca 3 registrado en los rellenos superiores de la excavación 2; m-n. Fragmentos de textiles paracas registrados en los rellenos disturbados en la excavación 2. ñ. Cerámica escultórica nazca 1 "Cahuachi Poychrome Inciced" (fotos: O. D. Llanos J. y A. Bachir Bacha, elaboración de los dibujos $O$. D. Llanos J.).

\section{Cerro Córdova en la órbita de influencia político-religiosa de Nasca}

La presencia del adobe cónico en la arquitectura de Cerro Córdova evoca la importancia que tuvo entre los paracas la imitación de materiales constructivos de prestigio nasca, lo que va de la mano con la manufactura de piezas de cerámica nasca 1 . Tal vez, hubo interés por parte de los dirigentes de Cerro Córdova de rememorar la arquitectura de Cahuachi y, con ello, ganar mayor prestigio. Esto implica que pobladores de Ocucaje se trasladaban ya hacia el valle de Nasca, quizás para participar 
en los rituales cíclicos que tenían lugar en el naciente centro político ceremonial de Cahuachi. El reconocimiento de una cierta cantidad de cerámica ocucaje 9-10 en Cahuachi (Orefici 2012: tomo I, 74) indica igualmente que poblaciones paracas visitaban ya el lugar, lo cual se explica por las colindancias territoriales y la interacción entre estas poblaciones vecinas, que incluía sin dudas relaciones de índole comercial.

Así, Cerro Córdova habría sido uno de los principales asentamientos paracas del valle de Ica dentro de la órbita nasca, cuyas poblaciones se involucraron en la difusión de los patrones simbólicos nasca. Ese fue el caso de las poblaciones de otros importantes sitios Paracas de Ocucaje, como Pinilla y Paraya, en cuyas superficies se identificó materiales nasca 1 (ver Williams y Pazos 1974; Cook 1994). Lo mismo se observa en otros establecimientos que, habiendo tenido un antecedente paracas (Ocucaje 9-10), cuentan también con materiales de Nasca 1, 2 y 3. No obstante, los hornos abiertos para la cocción de cerámica de Cerro Córdova - en cuyas paredes se encontraron restos de cerámica de estilo Nasca 2 y 3 - indican que este asentamiento fue uno de los polos de producción y de difusión de cerámica nasca en esta cuenca, sin duda, ya desde la etapa Nasca 1, como sugieren los restos de sus alfares registrados en los estratos de excavación en la Zona III. A esto debemos agregar las complejas "tumbas de tiro" provistas de paredes hechas con adobe cónico existentes en varias zonas de Ocucaje, como aquellas de Paraya y La Peña (ver Rossel Castro 1977: Fig. 12 y 13). Muchos de los materiales asociados a tales tipos de tumbas, ${ }^{14}$ especialmente los del cementerio de La Peña, cuentan con material suntuario de cerámica nasca 1 en el estilo Cahuachi Polychrome Incised y Modeled Thin. ${ }^{15}$ En la Huaca Aparcana de Ocucaje, se excavaron dos tumbas cuyo ajuar incluía recipientes de estilo Cahuachi Polychrome Incised and Modeled Thin: una botella escultórica ${ }^{16}$ (ver Lavalle 1986: 121) y un recipiente escultórico ${ }^{17}$ (ver Purin 1990: tomo II, fig. 36). En otra tumba del mismo lugar, se recuperó una botella negra de doble pico y asa puente en el estilo Cahuachi Polished Black Incised ${ }^{18}$ (ver Menzel 1971: lam. 7a). En una tumba del sitio de Pinilla, ${ }^{19}$ se registró un ajuar compuesto por una botella escultórica Cahuachi Polychrome Incised y Modeled Thin y un cuenco Cahuachi Stylus Decorated (ver Menzel 1971: lam. 7c y 7f).

Las tumbas de La Peña y Paraya en Ocucaje comparten amplias similitudes con aquellas de la fase Nasca Temprano reconocidas en el centro político ceremonial de Cahuachi, o con aquellas del sitio Nasca de Tunga en el valle de Las Trancas, esencialmente, el uso de adobes cónicos en las paredes de los mausoleos (ver Rossel Castro 1977: 143, 162). Es importante detallar que el estilo Cahuachi Polychrome Incised y Modeled Thin junto a los tipos Cahuachi Polychrome Incised Thick (ambos caracterizados por pintura precocción) fueron los alfares más complejos y sofisticados del corpus de Nasca 1 (ver Strong 1957: figs. 7f, 7g; 10; Carmichael 2016: fig. 5g). Sin embargo, estos especímenes que incluyen también antaras (ver Carmichael, 2016: Fig. 10, 11, 16, 17, 19, 20) abundan en los rellenos constructivos de Cahuachi, asociados a la arquitectura prístina de este centro político ceremonial, ligada a los adobes cónicos (Strong 1957: 21). Las excavaciones de Orefici en Cahuachi también señalan este tipo de alfar en diversos rellenos, aunque aún no han sido publicados de manera detallada. Su particularidad y compleja producción confirieron a estas piezas un alto valor suntuario, lo que sin duda explica su colocación en las tumbas que hemos citado en Ocucaje, las cuales habrían correspondido a personajes de alto rango a juzgar por su construcción.

La presencia de todos los alfares nasca 1 en los yacimientos de Ocucaje citados apoya la hipótesis de un proceso de adaptación cultural de los paracas de esta cuenca, incluidos los habitantes de Cerro Córdova, a la esfera de influencia política nasca, un proceso que como ya se señaló no parece ocurrir de la misma manera en Callango. En Ocucaje, esta influencia es remarcable por la presencia de objetos cerámicos suntuarios nasca, especialmente del tipo Cahuachi Polychrome Incised Thick. Uno de estos ejemplos es una botella escultórica nasca 1 de doble pico y asa puente descubierta en el sitio de Pinilla (ver Sawyer 1966: 98-99), posiblemente, proveniente de una tumba de élite. La botella en cuestión representa a la principal deidad del panteón político religioso nasca el «Ser Felino Antropomorfo", que luce en la cabeza una diadema frontal de ave, y lleva un cuchillo en la mano izquierda y una antara debajo de su rostro (Fig. 14ñ). Esta divinidad difiere de la imagen del Ser Oculado, principal divinidad paracas que abunda en la cerámica de las fases Ocucaje 8, 9-10, 


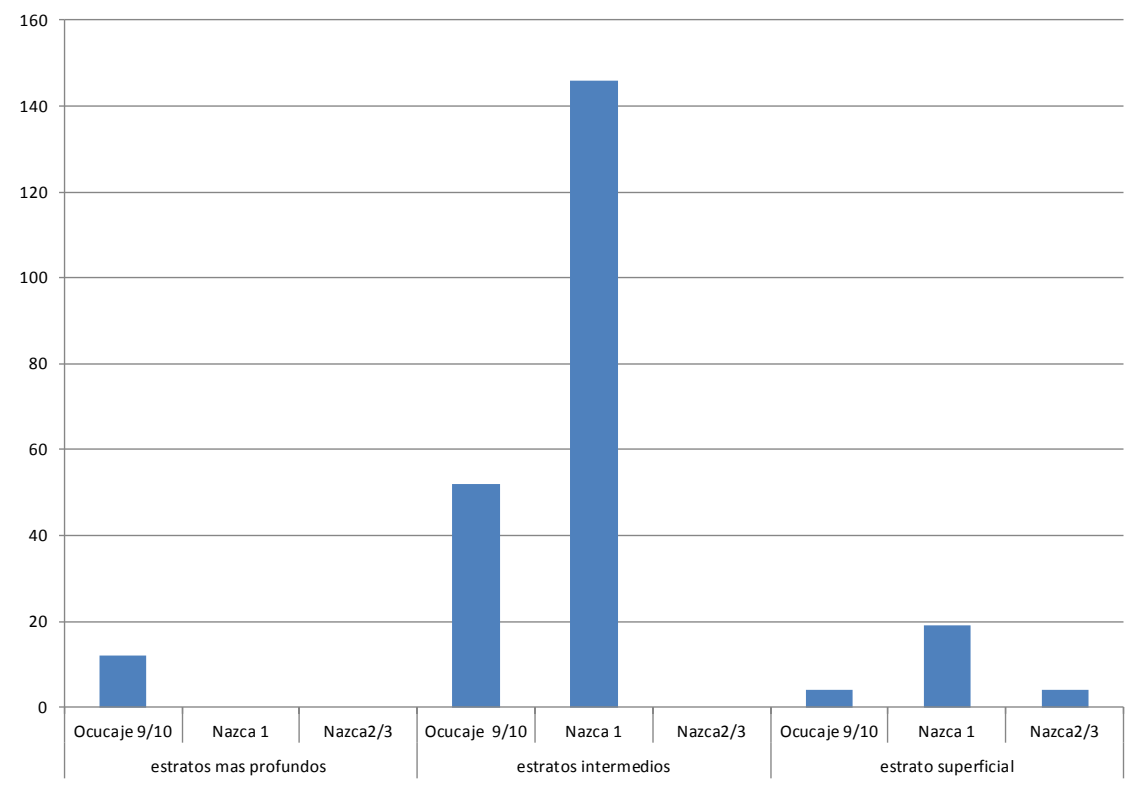

Figura 15. Frecuencia de cerámica de los estilos Ocucaje 9/10, Nazca 1 y Nazca2/3.

en tejidos suntuarios, así como en los frisos de Ánimas Altas. A partir de ello, se puede afirmar a ciencia cierta que el colapso de Ánimas Altas — centro del culto al Ser Oculado- significó el desprestigio de esta antigua divinidad. Sin duda, ello creó un vacío de poder simbólico entre los paracas, que fue llenado por las dinámicas político-religiosas de Nasca en torno al culto del Ser Antropomorfo Felino: una divinidad nasca materializada por la élite sacerdotal del centro político de Cahuachi, la cual acostumbraba tomar la apariencia de la divinidad (Llanos 2009: 166-167) y que muy posiblemente ostentaba atributos guerreros. De esta forma, la iconografía de la divinidad nasca en la botella descubierta en la tumba de élite de Pinilla expresa una ruptura simbólica con los patrones de la tradición paracas observada en las fases Ocucaje 9-10 y, especialmente, con la del Ser Oculado. La diadema de ave, los pendientes circulares y la antara asociados a la divinidad nasca de la botella de Pinilla son elementos inexistentes en la iconografía paracas; inclusive, no existen preformas simbólicas paracas que puedan ser tomadas en cuenta como evidencias de que el Ser Antropomorfo Felino de los nasca se origine en la iconografía paracas. Esto plantea su génesis fuera del territorio del valle de Ica, lo que nos orienta hacia el valle de Nasca. Igualmente, la simbología de la antara tiene una fuerte relación con los contextos definidos en Cerro Córdova, donde fragmentos de este instrumento musical fueron reconocidos solo en los niveles relacionados a materiales nasca e inexistentes en aquellos estratos ligados a la fase Paracas, como también están ausentes en los estratos de Ánimas Altas. Esto sugiere que las antaras de cerámica fueron más que nada una innovación nasca, introducida desde esta región hacia el valle de Ica.

\section{Conclusión}

Constituida la esfera político-religiosa nasca, las élites de Ocucaje y esencialmente las de Cerro Córdova debieron establecer alianzas con sus similares de Cahuachi, asentamiento que durante todo el período Nasca Temprano sería el único de la costa sur con arquitectónica monumental de gran importancia. Tal peculiaridad evoca en la larga duración, la capacidad de las élites nasca de Cahuachi de impedir el desarrollo político de otros asentamientos que pudiesen rivalizar con su poder. Estamos pues, en la costa sur, frente a un período político de centralización desde Cahuachi, 
cuyas élites lograron consolidarse como un Estado regional de tipo segmentario. No se trata de un Estado al estilo tradicional del despotismo oriental o de una teocracia, sino de una estructura estatal cuyo poder central reconocido a nivel macrorregional coexistía con focos de poder locales, sobre los cuales ejercía una autoridad relativa. La autoridad central, por tanto, no ejercía el monopolio absoluto de la fuerza, sino que la compartía con las élites regionales; así, estableció mecanismos sofisticados de persuasión política a fin de mantener alianzas y relaciones de confianza. De esta forma, las estrategias simbólicas y religiosas eran mucho más importantes en la política que aquellas del orden coercitivo, como muy bien evoca la complejidad de la iconografía nasca (ver Llanos 2009: 148, 149, 164), especialmente plasmada en su cerámica suntuaria, cuya dispersión estable es percibida en la larga duración desde Acarí hasta Chincha.

En este contexto, Cerro Córdova se inscribe como un polo administrativo dependiente y aliado de Cahuachi, lo que sin duda debió condicionar un cuerpo de élite privilegiado para la gestión administrativa del valle de Ica, una élite que, siendo de origen paracas, se sentía ahora integrada a la entidad política nasca. Tales interacciones son muy evidentes en los hornos de producción de cerámica nasca 2 y 3 , y en los restos de textiles suntuarios nasca reconocidos en Cerro Córdova (Figs. 14g-14l). La producción de objetos suntuarios con simbología nasca ejecutada por la gente de Cerro Córdova y de otros sitios de la cuenca de Ocucaje plantea una posición subalterna frente a los nasca. Si bien dichos contextos se encuentran sumamente disturbados en Cerro Córdova, es obvio que su existencia en el lugar responde a niveles de uso de una población identificada culturalmente con los patrones iconográficos nasca. No obstante, así como las élites nasca lograron integrar a su órbita política a los paracas, los elementos simbólico-religiosos paracas fueron también apropiados por estas élites nascas. Un ejemplo de esto es el registro de una diadema tejida, descubierta en Cahuachi (ver Silverman 1993: figs. 18.1, 18.2), similar a la que ostenta como insignia en la frente la máxima divinidad nasca. En este caso, dicha diadema presenta bordada en su parte trasera la imagen del Ser Oculado paracas. Teniendo en cuenta la idiosincrasia panteísta de las sociedades andinas, la diadema nasca citada explicaría esa dinámica de apropiación por parte de los nascas de las antiguas fuerzas religiosas de los paracas, especialmente, de aquellas poblaciones establecidas en la cuenca de Ocucaje, considerando que Callango se presenta casi despoblado. El estrecho vínculo político creado entre Cerro Córdova y Cahuachi quedaría bien expresado en las consecuencias de la coyuntura de colapso y abandono político de Cahuachi, ocurrida a mediados de 400 a 450 d.C., ya que su decadencia implicó casi simultáneamente el abandono de Cerro Córdova en la cuenca de Ocucaje.

\section{Agradecimientos}

El autor agradece al Ministerio de la Cultura del Perú, por otorgar los permisos para la realización de las investigaciones en Cerro Córdova, al CeRAP (EHESS) y a la directora del Programa Arqueológico Ánimas Altas A. Bachir Bacha. Asimismo, se agradece a los arqueólogos alumnos que participaron durante estas investigaciones bajo nuestra dirección, en especial a Marco Taquiri y Hernán Hurtado.

\section{Notas}

${ }^{1}$ El sitio D correspondería al área hoy ocupada por el asentamiento moderno de Córdova, en la parte baja, al sur del conjunto de Cerro Córdova.

${ }^{2}$ Se puede consultar la tabla «Lista de sitios y tumbas» (Kroeberg y Strong 1924: 101). En las tablas «Tipo de cerámica según estilos» y «Distribución de porcentajes por estilos» (ibid.: 102-104), el estilo Protonascoide desaparece y solamente se encuentra el denominado Proto Nasca, que hoy es denominado Nasca 3. En las láminas que presentan Kroeberg y Strong basándose en los materiales de Uhle (ibid: Plates 25 al 29), todas las piezas corresponden al estilo Nasca 3, salvo los especímenes c, f, de la Lámina 29, que corresponderían al estilo Ocucaje 9-10 de la secuencia Paracas, denominadas como Protonascoide. 
${ }^{3}$ Actualmente, esta arquitectura ha desaparecido debido a la ocupación moderna.

${ }^{4}$ Tampoco, se ha conservado. La descripción de adobes rectangulares indicaría vestigios de una ocupación del Horizonte Medio.

${ }^{5}$ Actualmente, el sitio 11-I01 también ha desaparecido.

${ }^{6}$ La gran extensión de Pinilla permite inferir que fue un sitio importante; lamentablemente, hoy los vestigios arqueológicos del yacimiento se encuentran en gran parte destruidos por el avance urbano y agrícola, a partir de lo cual quedan solo de manera dispersa algunos sectores del lugar.

${ }^{7}$ No se llegó a registrar el límite de profundidad de este relleno debido a la inestabilidad de los perfiles que podían colapsar.

${ }^{8}$ Tiene una profundidad de 0,50 metros.

${ }^{9}$ Vecinos del poblado de Córdova nos informaron que en el yacimiento existen algunos sectores con arquitectura provista de frisos que evocan guerreros danzando. Ellos señalan que la actividad de la huaquería los habría dańado.

${ }^{10}$ Este es uno de los motivos por los que Cerro Córdova es constantemente huaqueado. Nuestras excavaciones fueron también afectadas por el huaqueo durante las noches.

${ }^{11}$ Por ejemplo, antaras negras con decoración bruñida fueron registradas en los rellenos de construcción de la Gran Pirámide y del Templo Escalonado de Cahuachi (ver Orefici 2012: tomo 1, fig. 20, 21).

${ }^{12}$ Ello también sugiere que el desarrollo de antaras hechas en cerámica fue eminentemente parte de la tradición nasca.

${ }^{13}$ Burger (2007) analizó 238 puntas de proyectil de obsidiana recolectadas en 1959 en Ánimas Altas por Lawrence Dawson. Los lugareños de Callango informan que hasta una década atrás era fácil encontrar en superficie puntas de obsidiana. Su recolecta masiva para venderlas a los productores de artesanías ha hecho que desaparezcan de la superficie.

${ }^{14}$ En el valle alto de Ica, Pezzia registra igualmente una tumba con techo de adobes cónicos. El individuo se encontraba asociado a materiales que fueron identificados como Nasca 4 (Pezzia, 1968: 183), pero en realidad eran Nasca 3.

${ }^{15}$ Estas tumbas fueron excavadas por el hacendado Rubini. Destaca una botella que representa una canasta de lúcumas encontrada por Rubini en la Tumba 26 (ver Lavalle 1986: 119); otra ubicada en la Tumba 30 (ibid.: 120) representaba un halcón; o aquella de la Tumba 28 que representaba un zapallo (ibid.: 118).

${ }^{16}$ Se trata de la Tumba B, excavada por Rubini; la botella de pico y asa puente representa un halcón parado sobre una cesta.

${ }^{17}$ Es la Tumba 34, excavada por Rubini. Esta vasija representa dos personajes que portan una cabeza trofeo/ofrenda.

${ }^{18}$ Se trata de la Tumba C, excavada por Rubini.

${ }^{19}$ Es la Tumba 7, excavada por Rubini. El personaje de la botella es un pescador (ver Lavalle 1986: 120).

${ }^{20}$ Carmichael presenta diversos tipos de antaras polícromas nasca 1; en varias de ellas, se representó a la principal divinidad nasca que porta cuchillo y cabeza trofeo. Es muy posible que estas piezas provengan de Cahuachi. En efecto, en 1999, en uno de los edificios situado en una cima de uno de los edificios de Cahuachi en el sector Y1 (Ver Llanos 2009: fig. 10.31c), bajo la dirección de Orefici, 
el autor de este artículo registró un fragmento de antara nasca 1 con el diseño inciso de la principal divinidad nasca que portaba un cuchillo y blandía una cabeza trofeo/ofrenda (ver Llanos 2016: fig.10). En ese mismo edificio, sobre los niveles de los dos accesos con escalera de dicha estructura, se registró también una buena cantidad de antaras fragmentadas in situ.

\section{REFERENCIAS}

\section{Bachir Bacha, A.}

2013 Programme archéologique Animas Altas, Ica Pérou, rapport sur la campagne 2013, présenté à la commission consultative des recherches archéologiques à l'étranger, MAEDI, Paris.

2014 Programme archéologique Animas Altas, Ica Pérou, rapport sur la campagne 2014, présenté à la commission consultative des recherches archéologiques à l'étranger, MAEDI, Paris.

Bachir Bacha, A. y O. D. Llanos J.

2011 Arqueología e iconografía de los textiles Paracas descubiertos en Animas Altas, Ica, Perú, en: V. Solanilla (ed.), Actas de las V Jornadas internacionales sobre textiles precolombinos, 211-230, Universidad Autónoma de Barcelona, Publicaciones del Grup d'Estudis Precolombins 6, Barcelona.

2013 ¿Hacia un urbanismo paracas en Ánimas Altas/Ánimas Bajas (Valle de Ica)? A. Bachir Bacha y J. Dulanto (eds.), Paracas: nuevas evidencias, nuevas perspectivas, Boletin de Arqueología PUCP 17, 169-204.

Burger, R.

2007 Late Paracas obsidian tools from Animas Altas, Peru, Andean Past 8, 477-492.

Carmichael, $\mathrm{P}$.

2016 Proto-Nasca art and antaras, Nawpa Pacha 35 (2), 117-172. https://doi.org/10.1080/00776297.2015.1 108122

Cook, A.

1994 Informe final de las investigaciones de reconocimiento en la parte baja del valle de Ica, 1988-1990, Instituto Nacional de Cultura, Lima.

Isla, J.

2005 Proyecto Nasca-Palpa: un esfuerzo conjunto de arqueología arqueometría y fotogrametría, Kava-Indea-ETH, Lima

Isla J., M. Reindel, J. C. de la Torre

2003 Jauranga: un sitio Paracas en el valle de Palpa, costa sur del Perú, Beitrage zur Allgemeinen und Vergleichenden Archaologie 23, 227-274, Mainz am Rhein.

Kaulicke P.

1998 Max Uble y el antiguo Perú, Fondo Editorial de la Pontificia Universidad Católica del Perú, Lima.

Kaulicke, P., L. Fehren-Schmitz, M. Kolp-Godoy, P. Landa, Ó. Loyola, M. Palma, E. Tomasto, C. Vergel, B. Vogt

2009 Implicancias de un área funeraria del Período Formativo Tardío en el departamento de Ica, P. Kauilicke y Y. Onuki (eds.), El Período Formativo: enfoques y evidencias recientes. Cincuenta ańos de la Misión Arqueológica Japonesa y su vigencia, Boletín de Arqueología PUCP 13, 289-322.

King, $M$.

1983 The painted mummy bundles of Ocucaje (Peru), Indiana 1 (8), 243-266.

Kroeber A. y D. Strong

1924 The Uhle pottery collections from Ica, with three appendices by Max Uhle, Archaeology and Ethnology 21 (3), 95-133, University of California publications in American, Oakland.

Lavalle, J. A.

1986 Culturas precolombinas: Nazca, Banco de Crédito del Perú, Lima.

Llanos Jacinto, O. D.

2009 Le bassin du Rio Grande de Nazca, Pérou: Archéologie d’un État Andin 200 av. J.-C.- 650 ap. J.-C., British Archaeological Reports International Series, Archaeopress, Oxford. 
2016 Las interacciones regionales durante el Horizonte Antiguo y la aparición del Estado en la cuenca del Río Grande de Nazca, Nayra Kunan Pacha, Revista de Arqueología Social 1, 187-202, Lima.

Massey, S.

1990 Paracas, en: S. Purin (ed.), Inca-Peru 3000 d'histoire, tomo I, 144-155, Musées Royaux D’art et D’histoire, Bruxelles.

1992 Investigaciones arqueológicas en el valle Alto de Ica, en: D. Bonavia (ed.), Estudios de arqueología peruana, 215-236, Fomciencias, Lima.

Menzel, D.

1971 Estudios arqueológicos en los valles de Ica, Pisco Chincha y Cañete, Arqueología y Sociedad 6, 1-106, Lima.

\section{Menzel, D., J. Rowe, L. Dawson}

1964 The Paracas Pottery of Ica: A Study in Style and Time, University of California, Publications in American Archaeology and Ethnology 50, University of California Press, Berkeley.

Orefici, G.

2003 Nasca: hipótesis y evidencias de su desarrollo cultural, Documentos e Investigaciones 2, Brescia.

2012 Cahuachi. Capital teocrática nasca, tomos I y II, Universidad de San Martín de Porres, Lima.

Pezzia Assereto, A.

1968 Ica y el Perú precolombino, Empresa Editora Ojeda, Ica.

Purin, $S$.

1990 Inca-Peru 3000 d'histoire, tomo I y II, 144-155, Musées Royaux D'art et D’histoire, Bruxelles.

Rossel Castro, A.

1977 Arqueología sur del Perú, Editorial Universo, Lima.

Sawyer. A.

1966 Ancient Peruvian Ceramics, the Nathan Cummings collection. The Metropolitan Museum of Art, Zurich.

Silverman, $\mathrm{H}$.

1992 Estudio de los patrones de asentamiento y reconstrucción de la antigua sociedad Nasca, Boletín de Lima 82, 33-44.

1993 Cahuachi in the Ancient Nasca World, University of Iowa Press, Iowa City.

Strong, W. D.

1957 Paracas, Nazca, and Tiahuanacoid cultural relationships in south coastal Peru, Memoirs of the Society for American Archaeology 13, The Society for American Archaeology, Salt Lake City.

Unkel, I., B. Kromer, M. Reindel, L. Wacker, G. Wagner

2007 A chronology of the pre-Columbian Paracas and Nasca cultures in south Peru based on AMS 14c dating, Radiocarbon 49 (2), 551-564. https://doi.org/10.1017/S0033822200042466

Van Gijseghem, $\mathrm{H}$.

2004 Migration, agency, and social change on a prehistoric frontier: the Paracas-Nasca transition in the southern Nasca drainage, Peru, tesis de doctorado, Department of Philosophy, University of California, Santa Barbara.

Willians, C. y M. Pazos

1974 Inventario, catastro y delimitación del patrimonio arqueológico del valle de Ica, Instituto Nacional de Cultura, Centro de Investigación y Restauración de Bienes Monumentales, Lima.

Wurster, W.

1999 Max Uble (1856-1944), Verlag Phillipp Von Zabern, Mainz am Rheim, Alemania.

Ziolkowski M. , M. Pazdur, A. Krzanowski, A. Michczynski

1994 Andes Radiocarbon Database for Bolivia, Ecuador and Peru, Andean Archaeological Mission \& Gliwice Radiocarbon Laboratory, ArtGraph, Warszawa/Gliwice. 